\title{
CaMKII $\alpha$-Positive Interneurons Identified via a microRNA-Based Viral Gene Targeting Strategy
}

\author{
Marianna K. Keaveney, ${ }^{1 *}{ }^{\oplus}$ Bahar Rahsepar, ${ }^{1 *}$ Hua-an Tseng, ${ }^{1}{ }^{\circledR}$ Fernando R. Fernandez, ${ }^{1}$ Rebecca A. Mount, ${ }^{1}$ \\ Tina Ta, ${ }^{1}$ John A. White, ${ }^{1}$ Jim Berg, ${ }^{2}$ and Xue Han ${ }^{1}$ \\ ${ }^{1}$ Department of Biomedical Engineering, Boston University, Boston, Massachusetts 02215, and ${ }^{2}$ Allen Institute for Brain Science, Seattle, \\ Washington 98109
}

Single-cell analysis is revealing increasing diversity in gene expression profiles among brain cells. Traditional promotor-based viral gene expression techniques, however, cannot capture the growing variety among single cells. We demonstrate a novel viral gene expression strategy to target cells with specific miRNA expression using miRNA-guided neuron tags (mAGNET). We designed mAGNET viral vectors containing a CaMKII $\alpha$ promoter and microRNA-128 (miR-128) binding sites, and labeled CaMKII $\alpha^{+}$cells with naturally low expression of miR-128 (Lm128C cells) in male and female mice. Although CaMKII $\alpha$ has traditionally been considered as an excitatory neuron marker, our single-cell sequencing results reveal that Lm128C cells are $\mathrm{CaMKII}^{+}$inhibitory neurons of parvalbumin or somatostatin subtypes. Further evaluation of the physiological properties of Lm128C cell in brain slices showed that Lm128C cells exhibit elevated membrane excitability, with biophysical properties closely resembling those of fast-spiking interneurons, consistent with previous transcriptomic findings of miR-128 in regulating gene networks that govern membrane excitability. To further demonstrate the utility of this new viral expression strategy, we expressed GCaMP6f in Lm128C cells in the superficial layers of the motor cortex and performed in vivo calcium imaging in mice during locomotion. We found that $\mathrm{Lm} 128 \mathrm{C}$ cells exhibit elevated calcium event rates and greater intrapopulation correlation than the overall $\mathrm{CaMKII} \alpha^{+}$cells during movement. In summary, the miRNA-based viral gene targeting strategy described here allows us to label a sparse population of CaMKII $\alpha^{+}$interneurons for functional studies, providing new capabilities to investigate the relationship between gene expression and physiological properties in the brain.

Key words: calcium/calmodulin kinase type II; cell type classification; GCaMP6; optogenetics

Significance Statement

We report the discovery of a class of $\mathrm{CaMKII} \alpha^{+}$cortical interneurons, labeled via a novel miRNA-based viral gene targeting strategy, combinatorial to traditional promoter-based strategies. The fact that we found a small, yet distinct, population of cortical inhibitory neurons that express $\mathrm{CaMKII} \alpha$ demonstrates that $\mathrm{CaMKII} \alpha$ is not as specific for excitatory neurons as commonly believed. As single-cell sequencing tools are providing increasing insights into the gene expression diversity of neurons, including miRNA profile data, we expect that the miRNA-based gene targeting strategy presented here can help delineate many neuron populations whose physiological properties can be readily related to the miRNA gene regulatory networks.

Received Oct. 28, 2019; revised 0ct. 20, 2020; accepted 0ct. 22, 2020.

Author contributions: M.K.K. and X.H. designed research; M.K.K., B.R., H.-a.T., R.A.M., T.T., and J.B. performed research; M.K.K., B.R., H.-a.T., F.R.F., J.A.W., and X.H. contributed unpublished reagents/analytic tools; M.K.K., B.R., H.-a.T., and J.B. analyzed data; M.K.K., B.R., H.-a.T., F.R.F, J.B., and X.H. wrote the paper.

${ }^{*}$ M.K.K. and B.R. contributed equally to this work.

X.H. was supported by National Institutes of Health (NIH) Grants 1DP2-NS-082126 and 1R01-NS-08795001), and National Science Foundation Grant (BET-1848029; and M.K.K. was supported by NIH Grant F31-NS095465-02. Patch-seq experiments were funded by the Allen Institute for Brain Science. We thank Drs. Howard Gritton and Mike Romano for guidance regarding in vivo calcium imaging recordings and data analysis, and Dr. Kyle Hansen for sharing MATLAB code facilitating manual selection of ROls from preprocessed calcium images. We also thank the LAS team, Tissue Processing, and Molecular Biology teams at the Allen Institute for Brain Science for experimental support; and Brian Lee, Kristen Hadley, Rusty Mann, Lindsay Ng, Ram Rajanbabu, Jessica Trinh, and Katherine Baker at the Allen Institute for Brain Science for contributing toward Patch-seq recordings.

The authors declare no competing financial interests.

Correspondence should be addressed to Xue Han at xuehan@bu.edu.

https://doi.org/10.1523/JNEUROSCI.2570-19.2020

Copyright $\odot 2020$ the authors

\section{Introduction}

The brain is composed of many specialized cell subtypes, which together give rise to complex circuit dynamics and functions. Brain cells have traditionally been classified according to many criteria, including location, morphology, neurotransmitter contents, and electrophysiological properties (Zeng and Sanes, 2017). With advances in genetic tools, neuron types have been increasingly defined based on the expression of molecular markers, which allows for detailed characterization of functionality when associated with physiological phenotypes. However, neurons that express a common marker gene can still exhibit great diversity (DeFelipe et al., 2013; Tremblay et al., 2016), and many marker genes are only loosely related to the electrophysiology of the neuron subtype that they label. For example, 
CaMKII $\alpha$, the $\alpha$-subunit of the serine/threonine kinase CaMKII, has conventionally been used as a marker gene for excitatory neurons (Benson et al., 1992; Jones et al., 1994; Han et al., 2009; Nathanson et al., 2009; Han, 2012; Liu and Murray, 2012). However, the function of CaMKII $\alpha$ protein has not been specifically linked to the excitatory nature of these neurons.

Transcriptomic profiling has started to reveal that the gene expression diversity of neurons is too great to be encompassed by single marker genes (Roy et al., 2018). Early efforts focused on profiling gene expression from small cell populations taken from precise dissections (Belgard et al., 2011; Hawrylycz et al., 2012) or pools of sorted cells expressing common markers (Sugino et al., 2006; Cahoy et al., 2008; Zhang et al., 2014). However, population-level analyses have since been shown to mask the heterogeneities among individual cells. More recently, single-cell transcriptomic profiling has enabled the characterization of individual brain cells, revealing an increasing number of molecularly distinct classes of neurons (Pollen et al., 2014; Macosko et al., 2015; Usoskin et al., 2015; Zeisel et al., 2015; Tasic et al., 2016, 2018; Economo et al., 2018; Hodge et al., 2019). For example, two recent single-cell sequencing (seq) studies analyzed $\sim 20,000$ single brain cell nuclei, and identified 133 and 75 transcriptomically distinct neuron subtypes in mouse primary visual cortex (Tasic et al., 2018) and in human brain, respectively (Hodge et al., 2019). Combining single-cell transcriptional profiling and axonal reconstructions, Economo et al. (2018) subdivided excitatory pyramidal tract neurons into two subtypes with distinct projection patterns and motor functions. These single-cell studies underscore the genetic and functional diversity among brain cells and highlight the importance of developing new cell targeting strategies that can link transcriptomic profiles and functional properties.

Traditional promotor-based viral labeling techniques, however, cannot capture the increasing gene expression diversity among single cells. Recent advances in sequencing technologies have enabled comprehensive analysis of the relative levels and combinational patterns of microRNA (miRNA) expression with unprecedented scope and accuracy. miRNAs are small, 20- to 24-nt-long, noncoding RNAs that suppress gene expression by hybridizing to their complementary recognition sites within target mRNA transcripts (Bartel, 2009). A given miRNA tends to regulate sets of related genes, and its expression is usually correlated with that of its targets and can thus be closely linked to gene expression profiles. Accumulating evidence suggests that many miRNAs play important roles in regulating synaptic plasticity and neural network dynamics, and as well are implicated in neurologic and psychiatric disorders (Harraz et al., 2011; Xu et al., 2013). For example, miRNA expression has been used to discriminate between neurons and glia cells (Colin et al., 2009; Karali et al., 2011), and has been known to vary significantly across brain regions (Bak et al., 2008; Minami et al., 2014) and between cell types (He et al., 2012). Recently, miRNAs have been used as the basis for genetically targeting known neural subsets (Sayeg et al., 2015; Keaveney et al., 2018), as well as for the diagnosis of Huntington's disease (Reed et al., 2018) and therapy (Pfister et al., 2018). Thus, viral vector designs integrating miRNA regulation could provide a promising new strategy to study the functions of cells with a specific gene expression profile. Here, we demonstrate the use of the miRNA-guided neuron tag (mAGNET; Sayeg et al., 2015; Keaveney et al., 2018), combinatorial to traditional promotor-based gene targeting strategies for targeted gene expression in neurons on the basis of miRNA expression.

\section{Materials and Methods}

Viral vector cloning

Standard molecular cloning procedures (PCR and restriction enzyme digestion) were used to construct adeno-associated virus (AAV) vectors. To produce AAV-CaMKII $\alpha$-GCaMP6f, the $1.3 \mathrm{~kb}$ CaMKII $\alpha$ promoter (plasmid \#64545, Addgene) and the $1.35 \mathrm{~kb}$ GCaMP6f gene (plasmid \#40755, Addgene; Chen et al., 2013) were amplified via PCR and inserted between the ITRs (inverted terminal repeats) of an AAV-2 genomic vector (plasmid \#50954, Addgene; Lin et al., 2013) via EcoRI, AscI, and SpeI restriction sites. To produce AAV-CaMKII $\alpha$-GCaMP6f$4 \times 128$-mAGNET, four instances of the microRNA-128 (miR-128) recognition site (exact reverse complement of the mouse miRNA sequence) were added to the 3' untranslated region (UTR) of the GCaMP6f transgene by annealing single-stranded DNA oligonucleotides synthesized by DNA (Integrated DNA Technologies) and cloning into NotI sites. To produce AAV-CaMKII $\alpha$-mRuby2- $4 \times 128$-mAGNET, the mRuby2 reporter (plasmid \#54771, Addgene; Lam et al., 2012) was processed by PCR and used to replace GCaMP6f in AAV-CaMKII $\alpha$-GCaMP6f$4 \times 128$-mAGNET via AscI and SpeI sites. Viral vector sequences are available at GenBank (accession numbers: MW139899, for AAV-CaMKII-mRuby2-4 × 128-mAGNET; MW139900, for AAVCaMKII-GCaMP6f; and MW139901, for AAV-CaMKII-GCaMP6f$4 \times 128$-mAGNET)

\section{Virus preparation}

Recombinant AAV2.9 was packaged via triple transfections of the AAV2 transfer vector (AAV-CaMKII $\alpha$-GCaMP6f, AAV-CaMKII $\alpha$-GCaMP6f$4 \times 128$-mAGNET, or AAV-CaMKII $\alpha$-mRuby2- $4 \times 128$-mAGNET), cap-9 plasmid encoding the Rep and Cap proteins (serotype 9), and pXX680 helper packaging plasmid, into HEK293FT cells (R700-07, Thermo Fisher Scientific) using TransIT-293 transfection reagent (MIR 2700, Mirus Bio). Two days post-transfection, HEK cells were washed and lysed via multiple freeze-thaw cycles and sonication, and virus was purified from the lysate via polyethylene glycol precipitation (LV810A-1, System Biosciences). Viral titer was determined via real time PCR (RTPCR) (AAVpro Titration Kit version 2, Takara) to be $\sim 2 \mathrm{E} 12$ viral genomes $(\mathrm{vg}) / \mathrm{ml}$. Viral transduction was first tested in primary neuron cultures before in vivo injections were performed.

\section{Patch-seq experiments}

Tissue processing. All procedures were done in accordance with the National Institutes of Health Guide for the Care and Use of Laboratory Animals and were approved by the Allen Institute for Brain Sciences Institutional Animal Care and Use Committees. Mice (male and female) between the ages of postnatal day 45 (P45) and P70 were anesthetized with $5 \%$ isoflurane and intracardially perfused with 25 or $50 \mathrm{ml}$ of icecold slicing artificial CSF [ACSF; $0.5 \mathrm{~mm}$ calcium chloride (dehydrate), $25 \mathrm{~mm}$ D-glucose, $20 \mathrm{~mm}$ HEPES buffer, $10 \mathrm{~mm}$ magnesium sulfate, 1.25 $\mathrm{mm}$ sodium phosphate monobasic monohydrate, $3 \mathrm{~mm}$ myo-inositol, $12 \mathrm{~mm} \mathrm{~N}$-acetyl-L-cysteine, $96 \mathrm{~mm} \mathrm{~N}$-methyl-D-glucamine chloride (NMDG-Cl), $2.5 \mathrm{~mm}$ potassium chloride, $25 \mathrm{~mm}$ sodium bicarbonate, $5 \mathrm{~mm}$ sodium L-ascorbate, $3 \mathrm{~mm}$ sodium pyruvate, $0.01 \mathrm{~mm}$ taurine, and $2 \mathrm{~mm}$ thiourea, $\mathrm{pH} 7.3$, continuously bubbled with $\left.95 \% \mathrm{O}_{2} / 5 \% \mathrm{CO}_{2}\right]$. Coronal slices $(350 \mu \mathrm{m})$ were generated (model VT1200S Vibratome, Leica Biosystems). Slices were then transferred to an oxygenated and warmed $\left(34^{\circ} \mathrm{C}\right)$ slicing ACSF for $10 \mathrm{~min}$, then transferred to room temperature holding ACSF [ $2 \mathrm{~mm}$ calcium chloride (dehydrate), $25 \mathrm{~mm} \mathrm{D}-$ glucose, $20 \mathrm{~mm}$ HEPES buffer, $2 \mathrm{~mm}$ magnesium sulfate, $1.25 \mathrm{~mm}$ sodium phosphate monobasic monohydrate, $3 \mathrm{~mm}$ myo-inositol, 12.3 mM $N$-acetyl-L-cysteine, $84 \mathrm{~mm}$ sodium chloride, $2.5 \mathrm{~mm}$ potassium chloride, $25 \mathrm{~mm}$ sodium bicarbonate, $5 \mathrm{~mm}$ sodium L-ascorbate, $3 \mathrm{~mm}$ sodium pyruvate, $0.01 \mathrm{~mm}$ taurine, and $2 \mathrm{~mm}$ thiourea, $\mathrm{pH} 7.3$, continuously bubbled with $95 \% \mathrm{O}_{2} / 5 \% \mathrm{CO}_{2}$ ] for the remainder of the day until transferred for patch-clamp recordings.

Patch-clamp recording. Slices were bathed in warm $\left(34^{\circ} \mathrm{C}\right)$ recording ACSF [ $2 \mathrm{~mm}$ calcium chloride (dehydrate), $12.5 \mathrm{~mm}$ D-glucose, $1 \mathrm{~mm}$ magnesium sulfate, $1.25 \mathrm{~mm}$ sodium phosphate monobasic monohydrate, $2.5 \mathrm{~mm}$ potassium chloride, $26 \mathrm{~mm}$ sodium bicarbonate, and $126 \mathrm{~mm}$ sodium chloride, $\mathrm{pH} 7.3$, continuously bubbled with $95 \% \mathrm{O}_{2} / 5 \%$ 
$\left.\mathrm{CO}_{2}\right)$. The bath solution contained blockers of fast glutamatergic $(1 \mathrm{~mm}$ kynurenic acid) and GABAergic synaptic transmission ( $0.1 \mathrm{~mm}$ picrotoxin). Thick-walled borosilicate glass (catalog \#G150F-3, Warner Instruments) electrodes were manufactured (catalog \#PC-10, Narishige) with a resistance of 4-5 $\mathrm{M} \Omega$. Before recording, the electrodes were filled with $\sim 1.0-1.5 \mu$ l of internal solution with biocytin $[110 \mathrm{~mm}$ potassium gluconate, $10.0 \mathrm{~mm}$ HEPES, $0.2 \mathrm{~mm}$ ethylene glycol-bis (2-aminoethylether)- $N, N, N^{\prime}, N^{\prime}$-tetraacetic acid, $4 \mathrm{~mm}$ potassium chloride, $0.3 \mathrm{~mm}$ guanosine $5^{\prime}$-triphosphate sodium salt hydrate, $10 \mathrm{~mm}$ phosphocreatine disodium salt hydrate, $1 \mathrm{~mm}$ adenosine $5^{\prime}$-triphosphate magnesium salt, $20 \mu \mathrm{g} / \mathrm{ml}$ glycogen, $0.5 \mathrm{U} / \mu \mathrm{l}$ RNase inhibitor (Takara, 2313A), and $0.5 \%$ biocytin (catalog \#B4261, Sigma-Aldrich), pH 7.3]. The pipette was mounted on a Multiclamp 700B amplifier headstage (Molecular Devices) fixed to a micromanipulator (PatchStar, Scientifica).

Electrophysiology signals were recorded using an ITC-18 Data Acquisition Interface (HEKA). Commands were generated, signals processed, and amplifier metadata acquired using MIES (https://github.com/ AllenInstitute/MIES/), written in Igor Pro (WaveMetrics). Data were filtered (Bessel) at $10 \mathrm{kHz}$ and digitized at $50 \mathrm{kHz}$. Data were reported uncorrected for the measured $-14 \mathrm{mV}$ liquid junction potential between the electrode and bath solutions.

After formation of a stable seal and break-in, the resting membrane potential of the neuron was recorded (typically within the first minute). A bias current was injected, either manually or automatically using algorithms within the MIES data acquisition package, for the remainder of the experiment to maintain that initial resting membrane potential. Bias currents remained stable for a minimum of $1 \mathrm{~s}$ before each stimulus current injection. Upon completion of electrophysiology recording, the nucleus was slowly extracted from the neuron. The pipette containing internal solution, cytosol, and nucleus was removed from the pipette holder, and the contents were expelled into a PCR tube containing the lysis buffer (catalog \#634894, Takara).

cDNA amplification and library construction. We used the SMARTSeq v4 Ultra Low Input RNA Kit for Sequencing (catalog \#634894, Takara) to reverse transcribe poly(A) RNA and amplify full-length cDNA according to the manufacturer instructions. We performed reverse transcription and cDNA amplification for 21 PCR cycles in eight-well strips, in sets of 12-24 strips at a time. At least one control strip was used per amplification set, which contained four wells without cells and four wells with $10 \mathrm{pg}$ control RNA. Control RNA was either Mouse Whole Brain Total RNA (catalog \#MR-201, Zyagen) or control RNA provided in the SMART-Seq 4 kit. All samples proceeded through Nextera XT DNA Library Preparation (catalog \# FC-131-1096, Illumina) using the Nextera XT Index Kit V2 Set A (FC-131-2001). Nextera XT DNA Library prep was performed according to manufacturer instructions except that the volumes of all reagents including cDNA input were decreased to $0.4 \times$ or $0.5 \times$ by volume. Subsampling was conducted to a read depth of 0.5 million per cell.

Sequencing data processing. Fifty bp paired-end reads were aligned to GRCm38 (mm10) using a RefSeq annotation gff file retrieved from National Center for Biotechnology Information on January 18, 2016 (https://www.ncbi.nlm.nih.gov/genome/annotation_euk/all/). Sequence alignment was performed using STAR version 2.5.3 (Dobin et al., 2013) in two-pass mode. PCR duplicates were masked and removed using STAR option "bamRemoveDuplicates." Only uniquely aligned reads were used for gene quantification. Gene counts were computed using the R Genomic Alignments package summarize Overlaps function using "IntersectionNotEmpty" mode for exonic and intronic regions separately (Lawrence et al., 2013).

Mapping to neuron class or subclass. Neurons were mapped to class or subclass as described in the study by Gouwens et al. (2020). The Patch-seq transcriptomes were mapped to the mouse primary visual reference taxonomy tree (Tasic et al., 2018) in a top-down manner, trying to resolve broad classes first, followed by subclasses. For each single-cell transcriptome, starting from the root and at each branch point, we computed its correlation with the reference cell types using the markers associated with the given branch point (i.e., the genes that best distinguished groups at each branch of the tree) and then chose the most correlated branch. To determine the confidence of mapping, we applied 100 bootstrapped iterations at each branch point, and in each iteration, $70 \%$ of the reference cells and $70 \%$ of the markers were randomly sampled for mapping. This was done to evaluate the degree to which mappings were robust to the effects of individual genes or reference cells. The percentage of times a cell was mapped to a given leaf or branch point in the reference taxonomy was defined as the corresponding mapping probability. For each cell, the mapping probability was sorted, and then the cell was assigned to the class (for glutamatergic neurons) or the subclass (for GABAergic neurons) to which that cell mapped with highest probability. Each cell included in this dataset was mapped with a combined probability of $>0.95$ to the specific cell types within each assigned class or subclass.

Animal surgery for in vivo calcium imaging and slice physiology

All procedures were performed in accordance with the National Institutes of Health Guide for the Care and Use of Laboratory Animals and were approved by the Boston University Institutional Animal Care and Use and Biosafety Committees. First, surgery was performed to inject a mixture of AAV viruses. Mice were adult female C57BL/6 wildtype mice (Taconic Biosciences) that were 8 weeks old at the time of virus injection. AAV viruses (AAV-CaMKII $\alpha$-GCaMP6f + AAVCaMKII $\alpha$-mRuby $2-4 \times 128$-mAGNET or AAV-CaMKII $\alpha$-GCaMP6f$4 \times 128$-mAGNET + AAV-CaMKII $\alpha$-mRuby2- $4 \times 128$-mAGNET) were premixed at equal particle numbers. Next, $2.5 \mathrm{E} 8 \mathrm{vg}$ of each virus $(\sim 600 \mathrm{nl}$ total) was injected into motor cortex (mediolateral, +1.250 ; anteroposterior, +1.500 ; dorsoventral, -0.500 ). Seven days after the first surgery, mice underwent a second surgery for implantation of a sterilized custom imaging window that was previously assembled. The window consisted of a stainless steel imaging cannula [outer diameter (OD), $3.17 \mathrm{~mm}$; inner diameter, $2.36 \mathrm{~mm}$; height, $2 \mathrm{~mm}$; catalog \#B004TUE45E, AmazonSupply), fitted with a circular coverslip [size 0; OD, $3 \mathrm{~mm}$; Deckgläser Cover Glasses, catalog \#64-0726 (CS-3R-0), Warner Instruments] adhered using a UV-curable optical adhesive (Norland Products). To access the motor cortex, the skull directly above the injection site was carefully removed with a dental drill, then the imaging window was placed flush against the brain tissue and secured in place with Kwik-Sil and acrylic cement. During the same surgery, a custom aluminum head plate was attached to the skull with additional acrylic cement, posterior to the imaging window.

For the patch-clamp recording from parvalbumin (PV) and Lm128C neurons, another set of animals, either PV-tdTomato $(n=4)$ or PV-cre $(n=3)$ male and female mice, were injected with AAV-CaMKII $\alpha$ GCaMP $6 \mathrm{f}-4 \times 128-\mathrm{mAGNET}$ or an equal particle mixture of AAV-CaMKII $\alpha$-GCaMP6f- $4 \times 128$-mAGNET + AAV-flex-tdTomato, respectively. Injections were made at motor cortex (same coordinates as above).

\section{Slice electrophysiology}

Coronal sections of motor cortex were prepared from two sets of animals. One group was the CaMKII $\alpha$ mice coinjected with two AAVs and subjected to in vivo calcium imaging recordings. The other group included $\mathrm{PV}$-cre mice, coinjected with flex-tdTomato and AAV-CaMKII $\alpha$ GCaMP6f- $4 \times 128$-mAGNET. Animals were anesthetized with isoflurane, decapitated, and brains were removed and placed in oxygen-bubbled sucrose-substituted ACSF: $185 \mathrm{~mm} \mathrm{NaCl}, 2.5 \mathrm{~mm} \mathrm{KCl}$, $1.25 \mathrm{~mm} \mathrm{NaH}_{2} \mathrm{PO}_{4}, 10 \mathrm{~mm} \mathrm{MgCl}_{2}, 25 \mathrm{~mm} \mathrm{NaHCO}, 12.5 \mathrm{~mm}$ glucose, and $0.5 \mathrm{~mm} \mathrm{CaCl}_{2} .400 \mu \mathrm{m}$ slices were cut via microtome (catalog \#VT1200, Leica Microsystems) and incubated in $30^{\circ} \mathrm{C}$ ACSF consisting of $125 \mathrm{~mm} \mathrm{NaCl}, 25 \mathrm{~mm} \mathrm{NaHCO}_{3}, 25 \mathrm{~mm}$ D-glucose, $2 \mathrm{~mm} \mathrm{KCl}, 2 \mathrm{~mm}$ $\mathrm{CaCl}_{2}, 1.25 \mathrm{~mm} \mathrm{NaH}_{2} \mathrm{PO}_{4}$, and $1 \mathrm{~mm} \mathrm{MgCl}_{2}$ for $20 \mathrm{~min}$ and then cooled to room temperature.

To differentiate among the different cell types, slice recordings were performed using a two-photon imaging system (Thorlabs) with a modelocked Ti:Sapphire laser (Chameleon Ultra II, Coherent) set to wavelengths between 920 and $950 \mathrm{~nm}$, which was used to excite the Alexa Fluor 488, GCamP6f and tdTomato using a $20 \times$, numerical aperture 1.0 (Olympus) objective lens. In one group, Lm128C (labeled with the red fluorescent marker mRuby2) and CaMKII $\alpha$ cells (labeled with green fluorescent GCaMP6f), recordings were made from both green (overall $\mathrm{CaMKIIa}^{+}$cell population) and yellow cells $\left(\mathrm{CaMKII} \alpha^{+}\right.$and mRuby $\left.{ }^{+}\right)$. 
In the other experimental group, PV cells expressed red fluorescent tdTomato, Lm128C/PV ${ }^{-}$cells expressed green GCaMP6f, and Lm128C/ $\mathrm{PV}^{+}$cells coexpressed the two markers and appeared yellow.

Slice electrophysiology recording were done using a patch-clamp electrode with tips $(0.6-1 \mu \mathrm{m})$ pulled via horizontal puller (Sutter Instrument), and pipette resistance between 4 and $6 \mathrm{M} \Omega$. Pipettes were filled with intracellular fluid containing the following: $120 \mathrm{~mm}$ K-gluconate, $20 \mathrm{~mm} \mathrm{KCl}, 10 \mathrm{~mm}$ HEPES, $7 \mathrm{~mm}$ diTrisPhCr, $4 \mathrm{~mm} \mathrm{Na}_{2} \mathrm{ATP}, 2$ $\mathrm{mm} \mathrm{MgCl}_{2}, 0.3 \mathrm{~mm}$ Tris-GTP, and $0.2 \mathrm{~mm}$ EGTA, buffered to $\mathrm{pH} 7.3$ with $\mathrm{KOH}$. Alexa Fluor 488 hydrazide (Thermo Fisher Scientific) was added to this solution $(0.15 \% \mathrm{w} / \mathrm{v})$ to visualize the pipette under the twophoton imaging system.

For each recording, pipette capacitance neutralization and bridge balance compensation were performed before breaking in. Data were acquired using Multiclamp 700B (Molecular Devices) and a Digidata 1550 (Molecular Devices) with a sampling rate of $10 \mathrm{kHz}$. The mean \pm $\mathrm{SE}$ access resistance of all recordings was $31.6 \pm 5.2 \mathrm{M} \Omega$ ( $n=36$ cells).

\section{Electrophysiology data analysis}

Brain slice electrophysiology data analysis was performed in python with custom-written scripts using the pyABF package. Spike onsets were identified by a threshold of 10 on their first derivative, with their peak as the maximum value. Spike half-widths are the times between the two halves of the peak voltage amplitude. The rate of rise was calculated by dividing the change in voltage by the time from spike onset to peak. Rate of decay corresponds to time for voltage change from peak to the offset of a spike, defined as the minimum value of the first derivative of the voltage. To calculate the firing frequency versus injected current (FI) gain, the change in firing frequency from lowest firing rate to the highest firing rate was divided by the amount of current injected. Sag was calculated by subtracting the average membrane potential during the first $50 \mathrm{~ms}$ of hyperpolarizing current $(-50 \mathrm{pA})$ from the voltage during the last $100 \mathrm{~ms}$ of the step. The adaptation ratio was obtained by dividing the mean interspike intervals (ISIs) during the last $200 \mathrm{~ms}$ of spiking by the mean ISIs during the first $200 \mathrm{~ms}$ of spiking.

\section{Calcium imaging data acquisition}

Animal habituation. Following full recovery from the second surgery, animals were habituated to being head fixed and running on a 3D treadmill. The mice were habituated for $5,10,15$, and $20 \mathrm{~min} / \mathrm{d}$, respectively, for $4 \mathrm{~d}$.

Image acquisition with scientific complementary metal-oxide-semiconductor cameras. Animals were positioned underneath the microscope, and imaged while freely navigating the spherical treadmill. Image acquisition was performed via custom microscope equipped with a scientific complementary metal-oxide-semiconductor (sCMOS) camera (ORCA-Flash4.0 LT Digital CMOS camera C11440-42U, Hamamatsu). GCaMP6f fluorescence excitation was accomplished with a $5 \mathrm{~W}$ LED (460 nm; model LZ1-00B200, LED Engin). Custom microscope included a Leica N Plan $10 \times 0.25$ PH1 microscope objective lens, a dual-band excitation filter (catalog \#FF01-468/553-25), a dichroic mirror (catalog \#FF493/574-Di01-25 × 36), and a dual-band emission filter (catalog \#FF01-512/630-25, Semrock), and a commercial SLR lens focused to infinity as the tube lens (80-200 mm f/4 AI-s Zoom NIKKOR lens, Nikon).

A custom MATLAB script was used to trigger frame capture and to synchronize the acquisition of image data with movement information. TTL (transistor-transistor logic) trigger pulses were delivered to the camera using a common input/output interface (catalog \#USB-6259, National Instruments). Image acquisition was performed using HC Image Live (Hamamatsu). Because triggering was initiated using a MATLAB software loop, the exact sampling intervals varied based on demands of the Windows 7 operating system. In general, the sampling rate was $\sim 20 \mathrm{~Hz}$. For each image frame, exposure time was fixed at $20 \mathrm{~ms}$. Image data were stored as the multipage tagged image file format (mpTIFF). For a recording session of $20 \mathrm{~min}, \sim 48 \mathrm{~GB}$ of image data were stored, spreading across $12 \mathrm{mpTIFF}$ video files. The acquisition software was configured to buffer all frames in computer RAM during image acquisition to optimize acquisition speed. For each animal, full- session recordings of GCaMP6f fluorescence ( $20 \mathrm{~min}$ ) were performed using the specifications noted above.

Movement data acquisition. The spherical treadmill was constructed following the design of Dombeck et al. (2007). Briefly, the treadmill consisted of a 3D printed plastic housing and a Styrofoam ball supported with air. Movement was monitored using two computer USB mouse motion sensors affixed to the plastic housing at the equator of the Styrofoam ball. Each mouse sensor was mounted 3-4 mm away from the surface of the ball to prevent the interference of ball movement. The LED sensors projected on the ball surface $78^{\circ}$ apart. The $x$ - and $y$-surface displacement measured by each mouse sensor was acquired using a separate computer running a Linux OS (minimal CentOS 6). A multithreaded python script that asynchronously reads and accumulates mouse motion events was used to send packaged $<\mathrm{dx}, \mathrm{dy}\rangle$ data at $100 \mathrm{~Hz}$ to the image acquisition computer via a RS232 serial link. Motion data were received on the imaging computer using a MATLAB script that stored the accumulated $<\mathrm{dx}, \mathrm{dy}\rangle$ between frame triggers synchronized to each acquired image frame.

\section{Calcium imaging data analysis}

Motion correction, manual ROI selection, and $\Delta \mathrm{F} / \mathrm{F}$ time series calculation. Motion correction was performed using a custom python script as described in previous studies (Mohammed et al., 2016; Gritton et al., 2019). We first performed a series of image processing procedures to enhance the contrast and the characters of the image. Specifically, for each imaging session, we first generated a reference image by projecting the mean values of every pixel in the first mpTIFF video file saved containing $\sim 2000$ image frames. We then enhanced the contrast of the reference image and each frame as following. We removed the low-frequency component (potential nonuniform background) with a Gaussian filter (python scipy package, ndimage.Gaussian_filter, $\sigma=50$ ). We then enhanced the boundaries of the high-intensity areas to sharpen the image. In brief, we low-pass filtered the image with a Gaussian filter twice at two levels ( $\sigma=2$ and then 1). The intensity differences in two filtered images, which represent the boundaries of high-intensity areas, were multiplied by 100 and added back to the first low pass-filtered image $(\sigma=2)$, resulting in a boundary-sharpened image. Finally, to prevent the potential bleaching that may affect the overall intensity of the whole image, we normalized the intensity of each image by shifting the mean intensity to zero and dividing by the SD of the intensity. We then obtained the displacement between the location of the maximum coefficient and the center of the image by calculating the cross-correlations between the enhanced reference image and each enhanced frame. For each frame, the shift that countered the displacement was then applied to the original unenhanced image to complete the motion correction.

We then manually selected ROIs, using the maximum-minus-mean image for each GCaMP6f recording session. The center of each neural soma was registered using a circle with a radius of 6 pixels, corresponding to $7.8 \mu \mathrm{m}$. Raw fluorescence traces for each ROI were then extracted from motion-corrected video using a custom MATLAB script. For each ROI, we also normalized the trace by shifting the mean value to zero and scaling so that the maximum intensity equals $100 \%$.

Calcium event identification and waveform calculations. Because of the baseline shift of GCaMP6f fluorescence during each calcium imaging session, and the heterogeneity of signal quality among different ROIs within each field of view, it is difficult to detrend each fluorescence trace without affecting calcium event waveforms. Thus, we identified calcium waveforms using frequency domain features of the GCaMP6f fluorescence traces, where each calcium event is associated with an increase in low-frequency power $(<2 \mathrm{~Hz})$, because of the time constant of GCaMP6f responses.

We first calculated the spectrogram from raw fluorescence traces (MATLAB chronux, http://chronux.org/; mtspecgramc with tapers = [2 3 3 ] and window $=\left[\begin{array}{ll}1 & 0.05\end{array}\right]$ ), and averaged the oscillatory power $<2 \mathrm{~Hz}$. To detect any significant changes in power, we calculated the change in the power at each time point and identified all positive outliners corresponding to increases in power (MATLAB function "isoutliner"). For outliners that occurred at consecutive time points, we chose the first outliner as the onset of the power change. We then determined the offset of 
the power change as the first time point where the power decreases. We then mapped the onset and the offset time points of the power change back to the raw fluorescence traces for calcium event detection. We first identified the peak of each calcium event. Briefly, we examined the time points from the offset of the power change, to the second time point when the raw fluorescence trace decreased. Within this time window, we identified the peak fluorescence as the peak of a calcium event. The onset of a calcium event is determined as the time point when the raw fluorescence is at the minimum between the power change onset event and the calcium event peak. We excluded calcium events with an amplitude (the signal difference between the peak and the onset) $<3$ SDs of the fluorescence trace in a $10 \mathrm{~s}$ time window before the calcium event onset. In a few occasions, our event detection procedure may detect the same event more than once; therefore, we further refine the results by combining events that share overlapping time points.

To calculate the rise and fall time of the calcium event of each ROI, we first aligned all calcium events to their peak and averaged the traces within $5 \mathrm{~s}$ before and after the peak as the representative waveform (length, $10 \mathrm{~s}$ ). The rise and fall times were then determined using the representative calcium waveform for each ROI. The rise time is defined as the time from the time point when the intensity increases above threshold, defined as $1 \mathrm{SD}$ above the mean intensity during the $10 \mathrm{~s}$ window, to the peak of the waveform. The fall time is the time between the peak and the time point when the intensity dropped below the threshold. We excluded any ROIs that did not have well defined rise or fall times, such as the trace of the waveform did not fall below threshold after peak.

The size of each calcium event is calculated as the area of each calcium waveform above the threshold, calculated as described at each waveform of a given ROI and then averaged across all calcium events for a given ROI.

Pairwise correlation analysis between neuron pairs. We first binarized the calcium intensity trace by converting the time points within the rising phase of a calcium event (from event onset to peak, as identified above) to ones, and all other time points to zeros. The pairwise correlation coefficient from neuron A to neuron B is defined as the time points sharing ones in both $\mathrm{A}$ and $\mathrm{B}$, divided by the number of total time points of ones in A. To obtain the representative pairwise correlation coefficient for each neuron, we averaged the pairwise correlation coefficient from the neuron to every other neuron.

\section{Movement data analysis}

Spherical treadmill calibration. To map the Styrofoam ball movement to actual mouse linear velocity, we first calibrated the ball. We pinned the two sides of the ball at the equator perpendicular to each of the two computer mouse sensors, and then rotated the ball over a fixed distance perpendicular to the sensor to obtain the translation factors for calculating physical distance. The two computer mouse sensors were calibrated separately. Each computer mouse sensor reading was composed of a vertical reading and a lateral reading.

Linear velocity calculation. We calculated the linear displacement of the animal in two perpendicular directions. One direction ( $y$-axis of animal movement) is calculated from the vertical reading of one sensor. The other direction ( $x$-axis of animal movement) is calculated from the vertical readings of both sensors, using the following equations:

$$
\begin{gathered}
\frac{L-R \cos \theta}{\sin \theta} \\
Y=R
\end{gathered}
$$

Where $L$ is the vertical reading from the left sensor, $R$ is the vertical reading from the right sensor, and $\theta$ is the angle between the two sensors relative to the center of the ball that was fixed at $78^{\circ}$. The changes in linear distance were computed as follows: $D=\left(X^{2}+Y^{2}\right)^{\frac{1}{2}} \ldots D$ is the change in linear distance between two data sampling points, where each reading is triggered by TTL pulses as described above. To compute linear velocity, we divided the linear distance over time between sample points.
Identification of sustained periods of movement with high and low speed. We identified periods of high versus low linear speed similar to that described by Gritton et al. (2019). Briefly, we first smoothed each linear velocity trace using a low-pass Butterworth filter with a low-pass frequency of $1.5 \mathrm{~Hz}$ and then identified the time periods at which the smoothed linear velocity exceeded $5 \mathrm{~cm} / \mathrm{s}$ for at least $1 \mathrm{~s}$ (MATLAB commands "butter" and then "filtfilt" for zero-phase filtering). These periods were considered to be periods of movement with high speed. Similarly, periods during which the smoothed linear velocity of the mouse stayed at $<5 \mathrm{~cm} / \mathrm{s}$ for at least $1 \mathrm{~s}$ were considered periods of movement with low speed. If a period overlapped with the first or the last data point of a recording session, it is excluded from further analysis, because of the uncertainty of the start or the end of the period.

Calcium event properties across cell types during different movement periods. Calcium events considered to be in the high-speed or low-speed movement periods were used for event rate and pairwise correlation calculations as long as the onset of a calcium event occurred during one of these time periods. Calcium event properties (event rate and pairwise correlation) were averaged for each ROI, and the differences between high- and low-speed time periods were assessed using a paired $t$ test across all neurons.

\section{Immunohistology}

After the conclusion of in vivo calcium imaging recordings, animals were perfused with $4 \%$ PFA (except for animals used for slice electrophysiology). Brains were postfixed in $4 \%$ PFA at room temperature for $3 \mathrm{~h}$, cryoprotected in $30 \%$ sucrose, then flash frozen in OCT (optimal cutting temperature) compound. Frozen brains were sectioned (coronal) at $50 \mu \mathrm{m}$ on a cryostat, and slices were stored in PBS $+0.05 \%$ sodium azide. Brain slices were stained with antibodies against CaMKII $\alpha$ (1:50; catalog \#sc-13 082, Santa Cruz Biotechnology), followed by Alexa Fluor 633 goat anti-rabbit or goat-anti-guinea pig secondary antibody (1:1000; catalog \#A21071 or \#A21105, Thermo Fisher Scientific). All stained brained slices were imaged via confocal microscopy.

\section{Confocal imaging and quantification}

Confocal imaging was performed on an Olympus FV1000 scanning confocal microscope, using a $10 \times$ lens or a $60 \times$ water-immersion lens. $Z$-stacks were taken by imaging at $2 \mu \mathrm{m}$ intervals throughout the $50 \mu \mathrm{m}$ slices. Consistent laser settings were used for all imaging sessions, as follows: $488 \mathrm{~nm}$ laser 3.5\%, $350 \mathrm{~V}$; $543 \mathrm{~nm}$ laser $13 \%, 600 \mathrm{~V}$; and $633 \mathrm{~nm}$ laser $5 \%, 600 \mathrm{~V}$. GCaMP6 $\mathrm{f}^{+}$and/or mRuby $2^{+}$cell bodies were first identified throughout the stack, then categorized as immunopositive or immunonegative for specific antibody makers. Immunopositive cell counts were pooled across slices stained for the same marker for each animal and normalized to the total $\mathrm{Lm} 128 \mathrm{C}$ cell count across those slices. In this way, the proportion (percentage) of Lm128C cells that colocalize with each immunomarker was calculated independently. For each animal, we analyzed at least one to four nonoverlapping confocal stacks from two to six slices.

\section{Data availability}

The data that support the findings of this study are available from the corresponding author upon request. Viral vector sequences are available from GenBank (accession numbers: MW139899 for AAV-CaMKIImRuby2-4X128-mAGNET; MW139900 for AAV-CaMKII-GCaMP6f; and MW139901 for AAV-CaMKII-GCaMP6f-4X128-mAGNET).

\section{Results}

Viral labeling of a sparse population of CaMKII $\alpha^{+}$and low in miR-128 expression brain cells ( $\mathrm{Lm} 128 \mathrm{C}$ cells)

CaMKII $\alpha$ has conventionally been used as a cell type-specific marker gene for excitatory neurons in the cortex (Benson et al., 1992; Jones et al., 1994; Han et al., 2009; Nathanson et al., 2009; Han, 2012; Liu and Murray, 2012), and cortical CaMKII $\alpha^{+}$neurons have been shown to express miR-128 at a high level (He et al., 2012). However, when we incorporated miR-128 target sites in our earlier mAGNET designs, we consistently observed a 

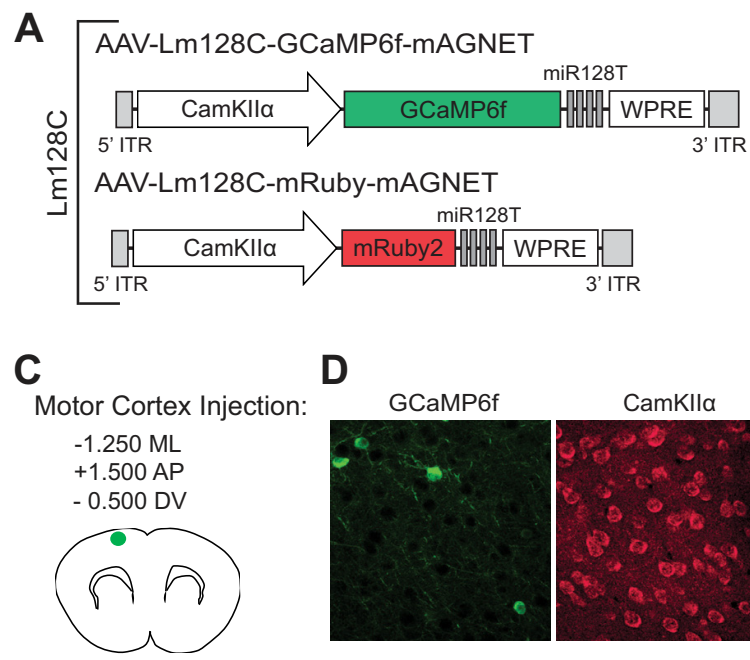

D
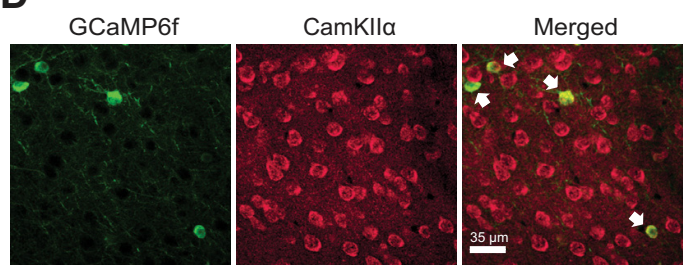

$\mathrm{E}$

CamKIla Animals

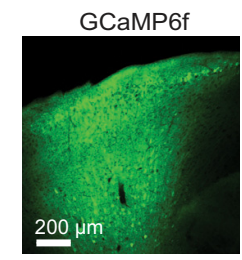

GCaMP6f

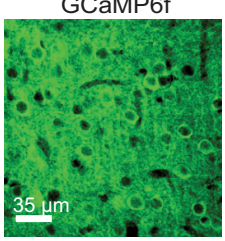

mRuby2

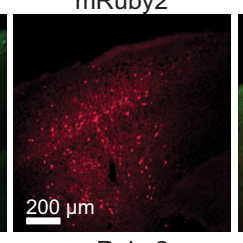

mRuby2

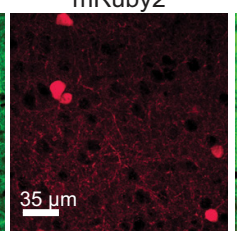

Merged

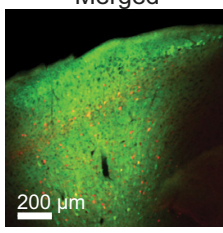

Merged

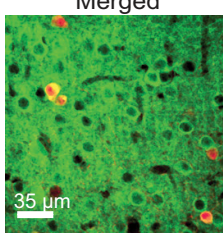

G

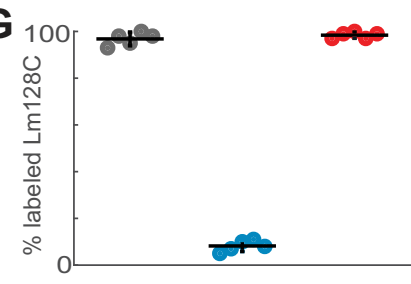

\% GCaMP6f+ Lm128C cells that are positive for CamKIl $\alpha$ antibody - (mRuby2+ Lm128C cells)/total GCaMP6f+ cells, in CamKIl $\alpha$ animals

- \% GCaMP6f+ Lm128C cells that express mRuby2, in Lm128C animals

B AAV-CamKIla-GCaMP6f-Control

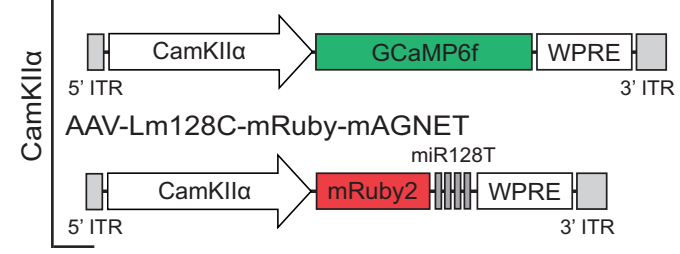

Figure 1. Lm128C versus overall CaMKIl $\alpha$ neurons in mouse motor cortex. $\boldsymbol{A}, \mathrm{AAV}$-Lm128C-GCaMP6f-mAGNET and AAV-Lm128C-mRuby-mAGNET vector designs. Lm128C animals ( $n=5$ ) were coinjected with these two AAVs for both in vivo calcium activity recordings and static labeling of Lm128C cells. B, AAV-CaMKIl $\alpha$-GCaMP6f-Control and AAV-Lm128C-mRuby-mAGNET vector designs. CaMKIl $\alpha$ animals ( $n=5$ ) were coinjected with these two AAVs for in vivo calcium activity recordings of overall CaMKIl $\alpha^{+}$cells and static labeling of Lm128C cells. $\mathbf{C}$, Schematic of stereotaxic virus injection site in mouse motor cortex. D, Representative confocal images of GCaMP6f fluorescence from Lm128C cells, immunofluorescence of a CaMKIl $\alpha$ antibody, and a merged overlay. $\boldsymbol{E}$, Representative low-magnification (top) and high-magnification (bottom) confocal microscopy images of the virus injection site in a CaMKIl $\alpha$ mouse, showing GCaMP6f expression in overall CaMKII $\alpha^{+}$neurons, mRuby2 expression in Lm128C neurons, and a merged overlay. $\boldsymbol{F}$, Same as $\boldsymbol{E}$, for a $\mathbf{L m} 128 \mathrm{C}$ mouse. $\boldsymbol{G}$, Quantification of labeled Lm128C cells. Percentage of $\mathrm{GCaMP6f}^{+} \mathrm{Lm} 128 \mathrm{C}$ cells that are also positive for CaMKIl $\alpha$ immunofluorescence, in Lm128C animals (left, gray); fraction of mRuby2 ${ }^{+}$Lm128C cells over the total GCaMP6f-expressing cells in CaMKIl $\alpha$ animals (middle, blue); percentage of ${\mathrm{GCaMP} f f^{+}} \mathrm{Lm} 128 \mathrm{C}$ cells that also express mRuby2 in Lm128C animals (right, red). Scatter plot shows individual animals (circles) and mean (horizontal bar) $\pm S D$ across animals ( $n=5$ mice each for each comparison, and at least 50 neurons were quantified per animal).

small fraction of labeled CaMKII $\alpha^{+}$neurons, indicating a lack of miR-128 expression in these CaMKII $\alpha^{+}$neurons (Sayeg et al., 2015). These results suggest that CaMKII $\alpha^{+}$cells can be further divided into subtypes based on their miR-128 expression levels. To characterize this unique neuron subset that is CaMKII $\alpha^{+}$ and low in miR-128 expression (low-miRNA-128 CaMKII $\alpha$ cells, Lm128C cells), we designed an AAV-Lm128C-mAGNET viral construct. AAV-Lm128C-mAGNET uses a $1.3 \mathrm{~kb}$ mouse CaMKII $\alpha$ promoter (Dittgen et al., 2004) and contains four repeats of the miR-128 target site (perfectly complimentary to the mouse miR-128 consensus sequence) within the $3^{\prime}$ UTR of the transgene (Fig. $1 A, B$ ). Using this Lm128C-mAGNET design, all infected $\mathrm{CaMKII} \alpha^{+}$cells produce mRNA transcripts because of the chosen promoter. However, in cells with a naturally high expression of miR-128, gene transcripts are knocked down, whereas in cells with low levels of miR-128, gene transcripts survive to be translated.

To statically label Lm128C neurons, we delivered a red fluorescent reporter mRuby2 in the AAV-Lm128C-mAGNET viral vectors (Fig. $1 A, B$ ). Additionally, to facilitate in vivo calcium activity recordings from either Lm128C neurons or the overall $\mathrm{CaMKIIa}^{+}$population, we also codelivered another AAV bearing the calcium indicator GCaMP6f under the regulation of the CaMKII $\alpha$ promoter, with or without the cassette of miR128 binding sites (Fig. $1 A, B$ ). CaMKII $\alpha$ mice were injected with AAV-CaMKII $\alpha$-GCaMP6f-Control (Fig. $1 A$ ) to label all $\mathrm{CaMKII} \alpha^{+}$neurons with GCaMP6f. Lm128C mice were injected with AAV-Lm128C-GCaMP6f-mAGNET (Fig. $1 B$ ) to label only Lm128C neurons with GCaMP6f. Both groups were also coinjected with AAV-Lm128C-mRuby-mAGNET to label Lm128C cells with mRuby2. All injections consisted of $\sim 600 \mu \mathrm{l}$ of a 1:1 virus mixture (1E9 vg/virus) in superficial motor cortex (Fig. 1C).

At the conclusion of in vivo experiments, we processed the brain tissue and characterized mRuby2-labeled Lm128C cells via confocal microscopy. We found that Lm128C neurons are sparsely distributed across all cortical layers in mouse motor cortex (Fig. 1E,F). Staining with an anti-CaMKII $\alpha$ antibody showed that $99 \pm 1 \%$ of $\mathrm{Lm} 128 \mathrm{C}$ neurons expressed CaMKII $\alpha$ 
A

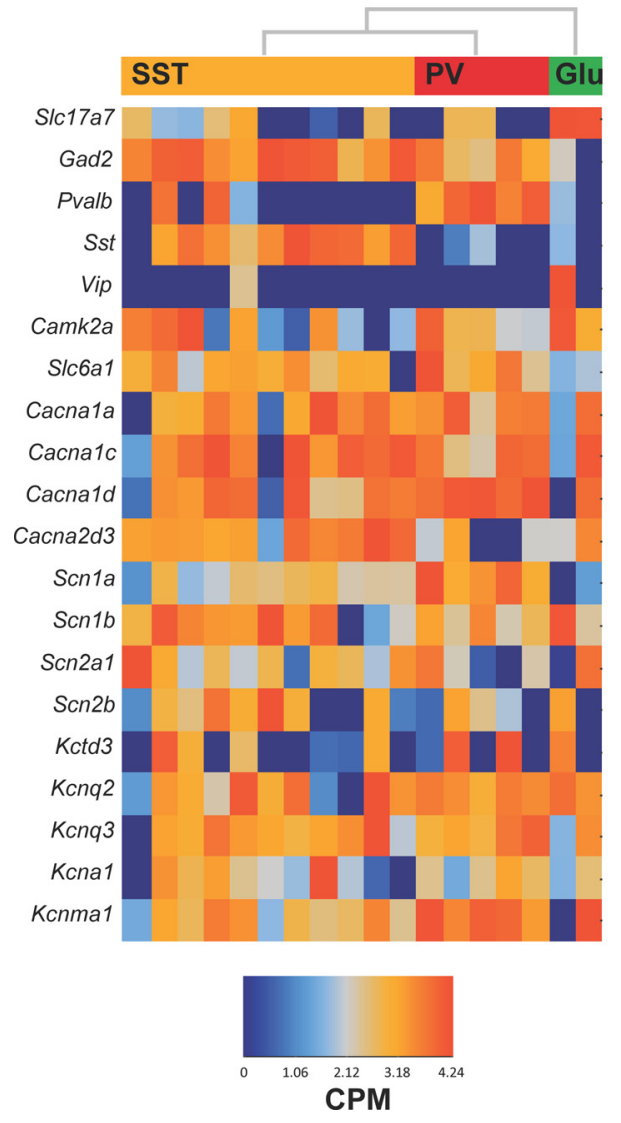

B

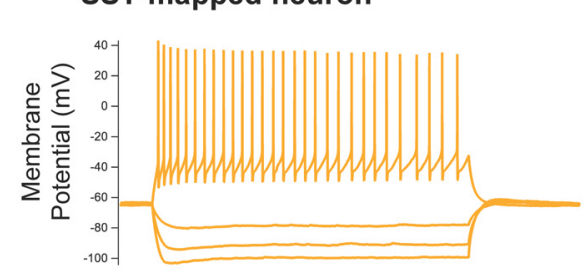

PV-mapped neuron

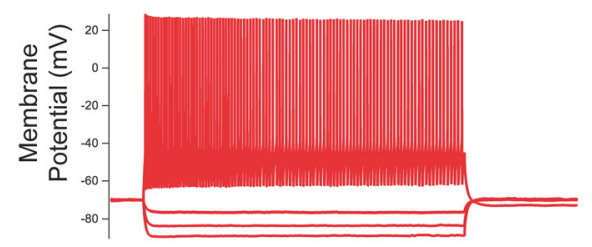

Glutamatergic-mapped neuron
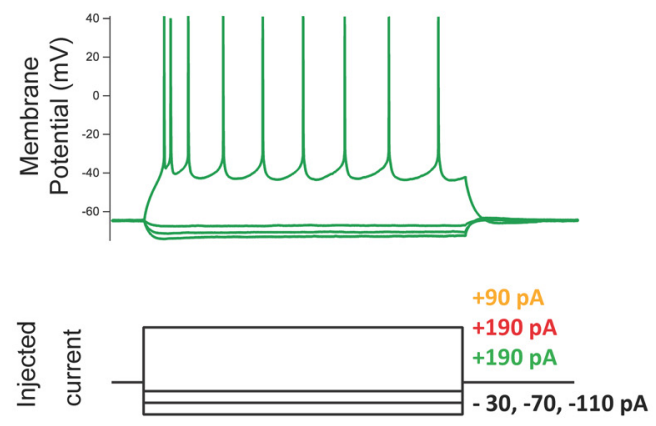

C
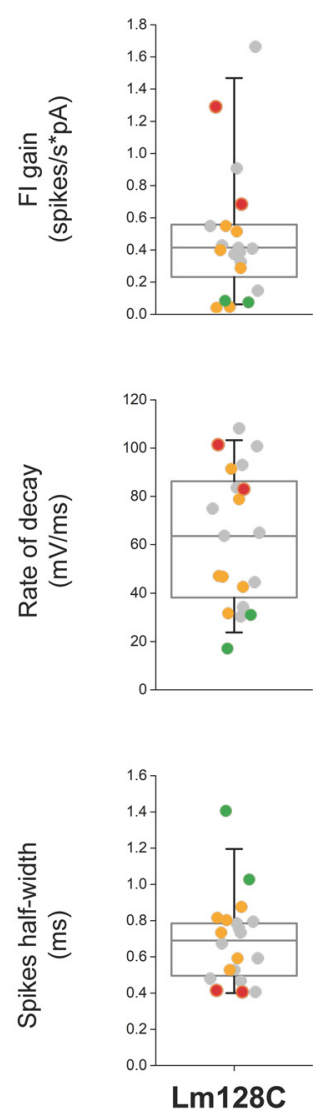

Figure 2. Single-cell sequencing analysis of $\operatorname{Lm} 128 \mathrm{C}$ cells. $A$, Heat map showing gene expression values for individual $\operatorname{Lm} 128 \mathrm{C}$ cells in mouse motor cortex slices using the Patch-seq technique $(n=18)$. Color in top bar indicates the subclass that each cell maps to, and the corresponding dendrogram. Orange, SST; red, PV; green, glutamatergic (Glu). B, Representative electrophysiology traces from cells that map to SST, PV, and glutamatergic subclasses. One-second-long current injections to hyperpolarized potentials show passive properties, while spike train properties are shown with injections for each cell $60 \mathrm{pA}$ above rheobase. C, Box plots of population electrophysiology responses. Top, Fl gain, calculated as the change in firing frequency from lowest firing rate to highest firing rate, divided by the current injected. Middle, Rate of spike decay, calculated as the time from peak voltage to the minimum value of the first derivative of voltage. Bottom, Spike half-width, calculated as the time between the two midpoints of the spike waveforms. Individual data points for each cell are overlaid, with color corresponding to the same mapping as in $\boldsymbol{A}$ and $\boldsymbol{B}$, with gray indicating cells without successful transcriptomic processing.

(Fig. $1 D, G)$, confirming that CaMKII $\alpha$ promoter exclusively labeled CaMKII $\alpha$-expressing neurons. We then further quantified the percentage of GCaMP6f-expressing cells (overall CaMKII $\alpha^{+}$ neurons) that also expressed mRuby2 (Lm128C marker) in CaMKII $\alpha$ animals ( $n=1334$ cells from five mice) and found that Lm128C neurons constitute $8 \pm 2 \%$ of the overall CaMKII $\alpha^{+}$ neuron population (Fig. $1 E, G$ ). Similar colocalization analysis in Lm128C animals revealed that $98 \pm 2 \%$ of GCaMP6f-expressing neurons (Lm128C marker) also expressed mRuby2 (Lm128C marker; $n=347$ cells from five mice), confirming that coinjected AAVs transduced nearly all of the same cells (Fig. 1F,G).

Single-cell transcriptomic analysis reveals that $\mathrm{Lm} 128 \mathrm{C}$ cells express CaMKII $\alpha$ and GABA transporters, and can be mapped to mainly parvalbumin-expressing or somatostatinexpressing subtypes

To assess the gene expression patterns and the corresponding physiological properties of Lm128C cells, we performed singlecell mRNA sequencing of Lm128C cells. We injected mice with AAV-Lm128C-GCaMP6f-mAGNET in the superficial motor cortex region and performed patch-seq analysis of GCaMP6f ${ }^{+}$ Lm $128 \mathrm{C}$ cells. We found that 16 of the 18 cells transcriptomically analyzed were GABAergic, expressing glutamate decarboxylase genes [glutamic acid decarboxylase-1 (GAD1) and GAD2], and the GABA transporter gene Slc6a1 (Fig. 2A). Two of the 18 cells analyzed exhibited low levels of expression of Slc17a7, a vesicular glutamate transporter gene, indicative of excitatory nature. Based on the gene clusters generated in our previous study using the single-cell RNA-seq dataset in the mouse visual cortex (Tasic et al., 2018), the GABAergic Lm128C neurons mapped to the somatostatin (SST)-expressing (11 cells) or PV-expressing (5 cells) branches of the transcriptomic tree. The electrophysiological features obtained in these neurons are in general consistent with the faster spiking properties of these interneuron subtypes (Fig. 2B,C).

Consistent with our antibody staining and colocalization analysis with CaMKII $\alpha$ (Fig. $1 D, G$ ), all but one cell analyzed contained significant levels of CaMKII $\alpha$ mRNA. miR-128 has been shown to regulate the expression of several ion channels that govern membrane excitability (Tan et al., 2013); thus, we focused our analysis on these genes. We observed consistent expression of most ion channel genes that have been shown to be regulated by miR-128, and are known to regulate membrane excitability, such as Cacna $1 \mathrm{a} / \mathrm{b} / \mathrm{c} / \mathrm{d}$ and Cacna2d3 (families of voltage-gated calcium channels), Kcnq2/3 (potassium channels), and Scn1a/ $1 \mathrm{~b} / 2 \mathrm{~b}$ (sodium channels; Fig. $2 \mathrm{~A}$ ). The presence of these proteins that are known to be negatively regulated by miR-128 confirmed that Lm128C cells are indeed low in miR-128 expression. 
A

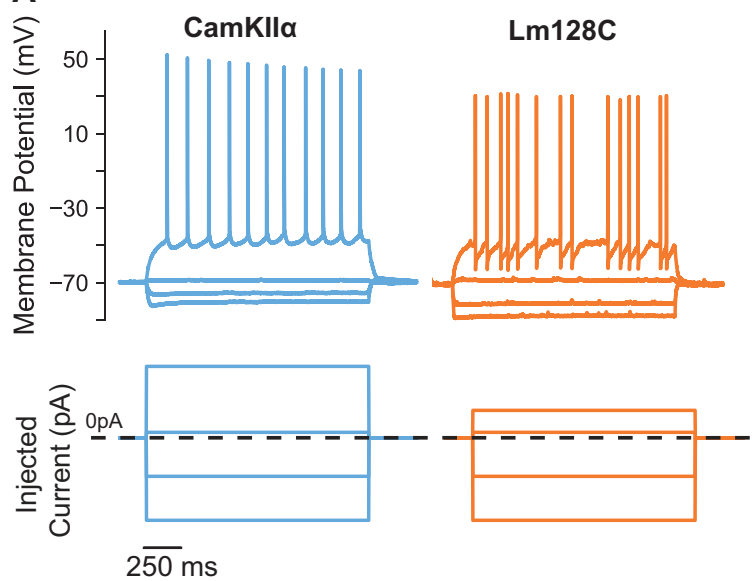

Ci

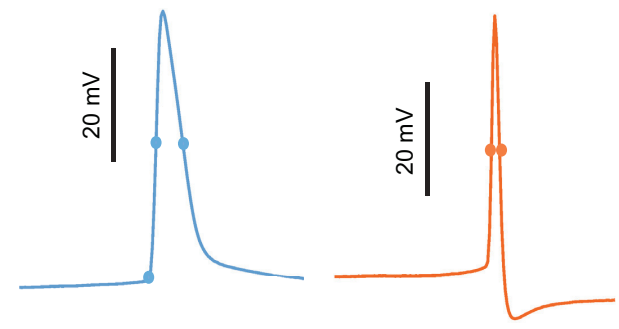

Bi

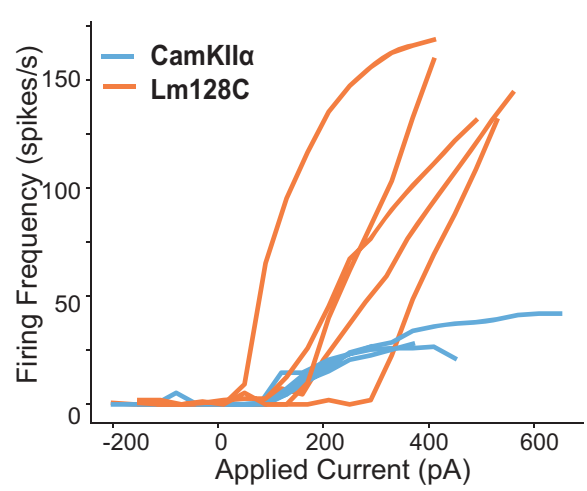

Cii

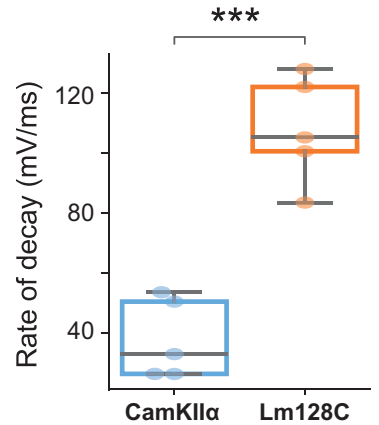

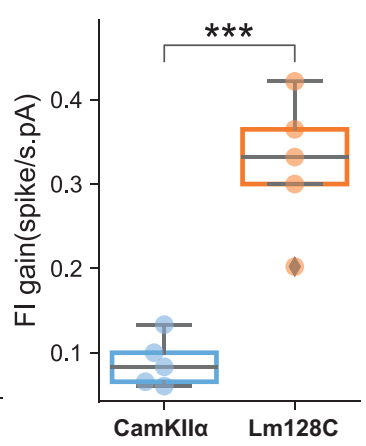

$\mathrm{Bii}$

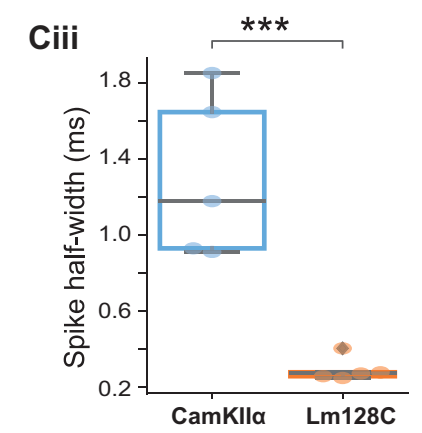

Figure 3. Distinct electrophysiological properties of $\mathrm{Lm} 128 \mathrm{C}$ and overall CaMKII $\alpha$ neurons. $\boldsymbol{A}$, Representative voltage responses (top) of a CaMKIll $\alpha$ neuron (blue) and an $\mathrm{Lm} 128 \mathrm{C}$ neuron (orange) to stepped current injections (bottom). Bi, FI for each neuron recorded ( $n=5$ each). Bii, Fl gain (***p=0.001). Ci, Representative average spike shape of a CaMKIll $\alpha$ neuron (blue) and an $\mathrm{Lm} 128 \mathrm{C}$ neuron (orange). Dots indicate spike threshold, and spike waveform midpoint used for calculating spike half-width. Cii, Rate of spike decay ( $* * * p=0.0009)$. Ciii, Spike half-width $(* * * p=0.0006)$. All $p$ values were calculated using two-tailed unpaired Student's $t$ test.

Together, these results demonstrate that Lm128C cells exhibit electrophysiological and transcriptomic features consistent with a population of inhibitory interneurons, including both PV and SST subtypes, and with gene expression profiles consistent with low miR-128 expression.

\section{Lm128C neurons exhibit biophysical properties that are characteristic of fast-spiking interneurons}

To further characterize the biophysical properties of Lm128C cells, we performed two-photon guided patch-clamp electrophysiological recordings in motor cortex brain slices prepared from mice previously used for in vivo calcium imaging experiments. We identified CaMKII $\alpha$ cells as those only positive for GCaMP6f, and Lm128C cells as those positive for both GCaMP6f and mRuby2 (as detailed in Fig. 1A). Electrophysiology analysis was performed on neurons in the superficial cortex region, primarily layer $2 / 3$ cells that can also be analyzed using wide-field calcium imaging. We measured the voltage responses to step current injections in both CaMKII $\alpha$ (Fig. $3 A$, blue) and Lm128C cells (Fig. $3 A$, orange). The slope of the spike frequency-current $(\mathrm{F}-\mathrm{I})$ relationship was significantly steeper for Lm128C cells (Fig. 3B), suggesting heightened membrane excitability. Additionally, Lm128C cells exhibit narrower spike half-width, and faster spike decay rate than the overall CaMKII $\alpha$ cell population (Fig. 3Ci). Increased excitability, narrower spikes, and greater afterhyperpolarization are characteristics of fast-spiking interneurons. Together, these results further confirm that the electrophysiological properties of the overall CaMKII $\alpha$ cells are consistent with those typically observed in pyramidal cells, whereas the properties of Lm128C neurons are consistent with those typically observed in fast-spiking interneurons (McCormick et al., 1985; Suter et al., 2013; Gonzalez-Sulser et al., 2014; Ferrante et al., 2017). miR-128 has been shown to regulate the expression of several ion channels and signaling components of the extracellular signal-regulated kinase 2 network that governs neuronal excitability, and deficiency in this miRNA impacts motor function (Tan et al., 2013). The observed elevated membrane excitability in Lm128C neurons, with naturally low levels of miR-128 expression, is consistent with the role of miR-128 in regulating membrane excitability.

\section{Lm128C interneurons regardless of PV expression have fast-spiking biophysical profiles similar to that of $\mathrm{PV}^{+}$ interneurons}

Single-cell sequencing analysis suggested that Lm128C neurons can be mapped to either the PV or the SST subtype based on their transcriptomic properties (Fig. 2). To further assess biophysical differences between the two subclasses of Lm128C cells, we performed patch-clamp recording in PV-tdTomato mice injected with AAV-Lm128C-GCaMP6f-mAGNET $(n=4)$, and PV-cre mice $(n=3)$ injected with both AAV-flex-tdTomato and AAV-Lm128C-GCaMP6f-mAGNET. In both cases, $\mathrm{PV}^{+}$cells expressed tdTomato. Lm128C/PV ${ }^{-}$neurons, presumable SSTmapped Lm128C cells, are positive for GCaMP6f and negative for tdTomato, LM128c/PV ${ }^{+}$neurons are positive for both GCaMP6f and tdTomato, and $\mathrm{PV}^{+}$cells are positive for tdTomato and negative for GCaMP6f. Electrophysiology results revealed that all three populations exhibited steep F-I curves, narrow spike shapes, and large afterhyperpolarizations following the repolarization of spikes (Fig. 4B,C), consistent with the fast-spiking features, 
A
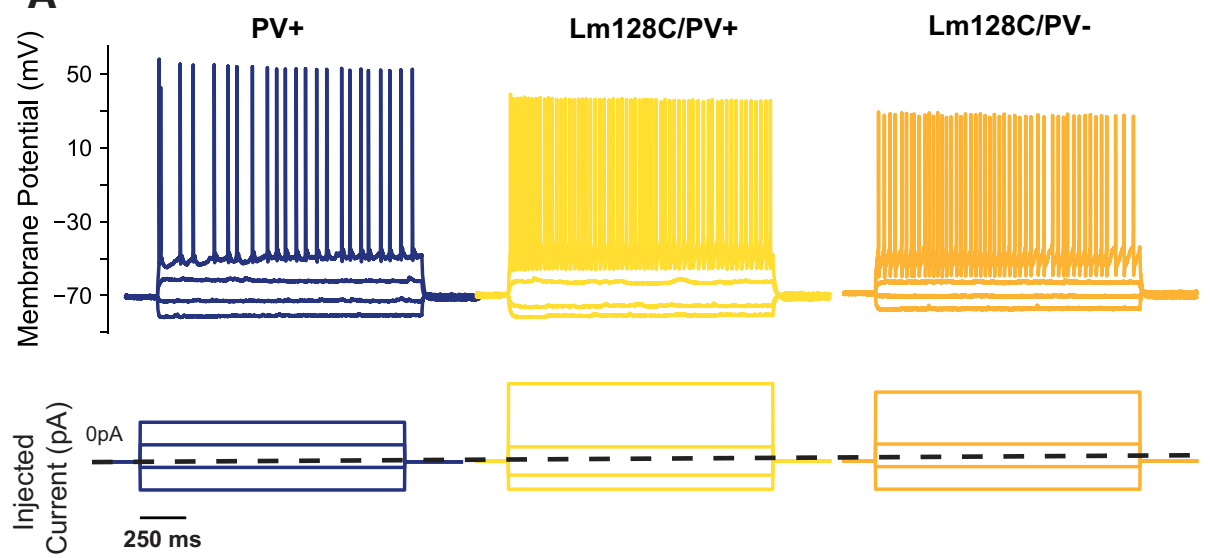

Lm128C/PV+

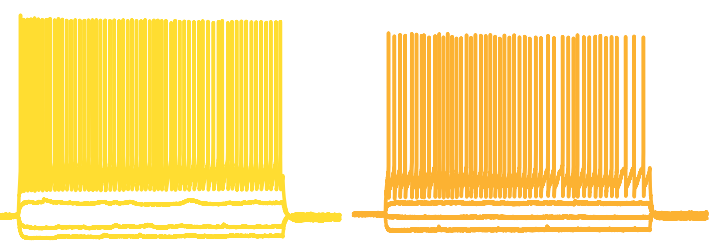

Bii

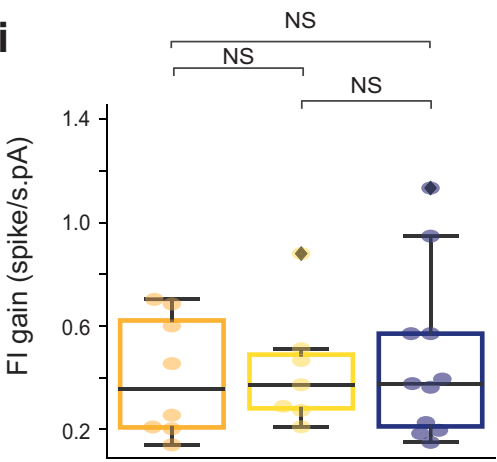

Ei

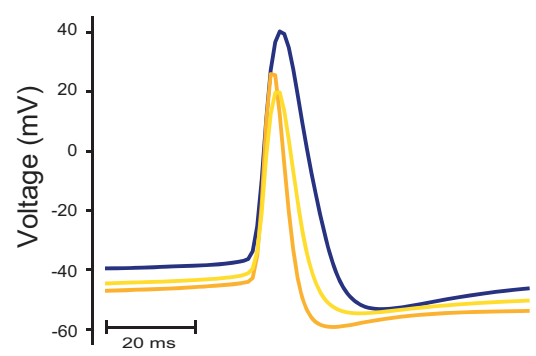

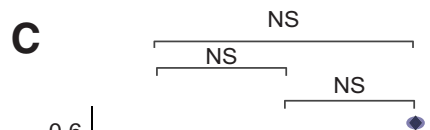
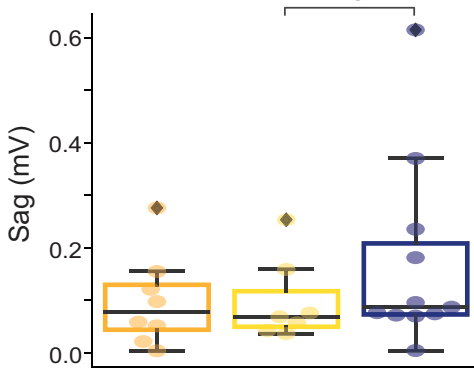

Eii

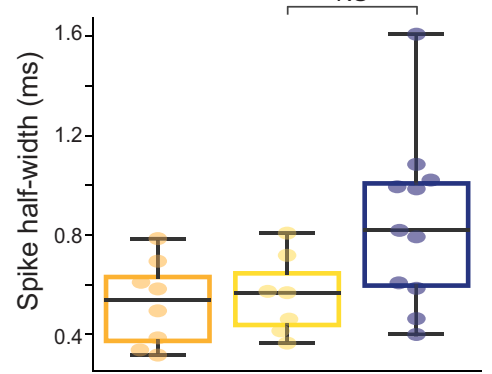

Bi
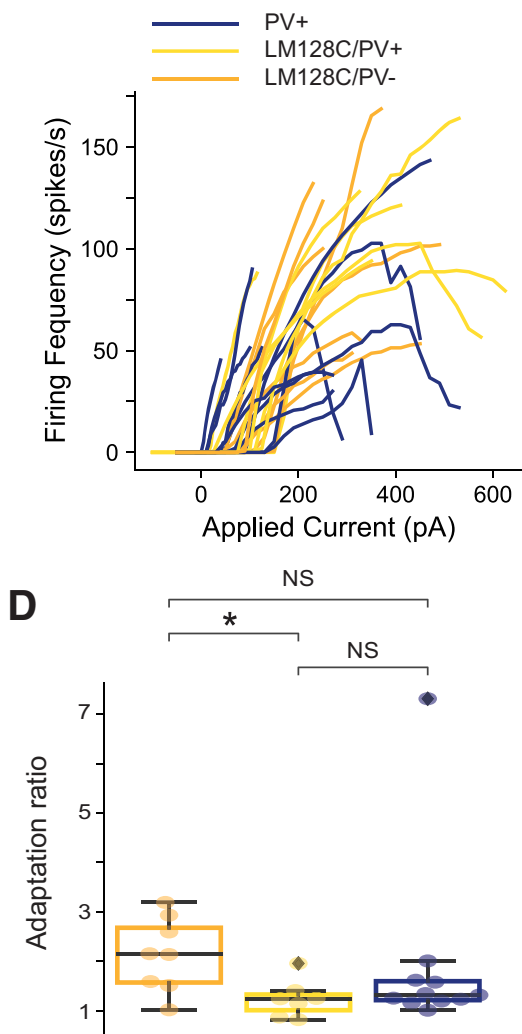

Eiii

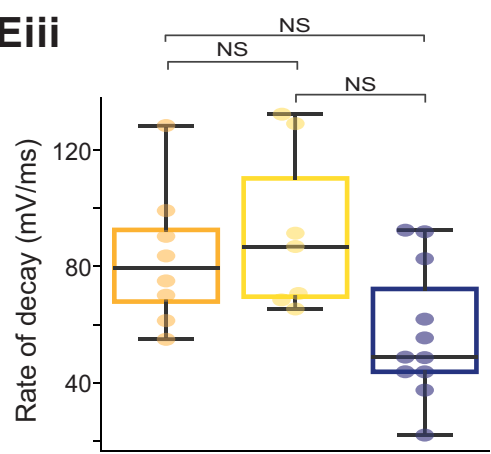

Figure 4. Electrophysiological properties of $\mathrm{Lm} 128 \mathrm{C}$ interneuron subtypes. $\boldsymbol{A}$, Representative voltage responses (top) of a $\mathrm{PV}{ }^{+}$interneuron (navy), an $\mathrm{Lm}^{2} 28 \mathrm{C}$ neuron positive for PV (Lm128C/PV ${ }^{+}$, orange), and an $\mathrm{Lm} 128 \mathrm{C}$ neuron negative for PV (Lm128C/PV', yellow), to stepped current injections (bottom). Bi, Fl for each neuron recorded $\left(n=10\right.$ neurons for PV ${ }^{+}, n=9$

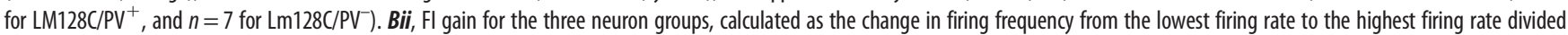
by the amount of current injected. C, Sag for the three neuron groups. $\boldsymbol{D}$, Adaptation ratio for the three neuron groups $(* p=0.03)$. Ei, Representative average spike shapes of the three neuron populations. Eii, Spike half-width, calculated as the time between the two midpoints of the spike waveforms. Eiii, Rate of decay, the time from peak voltage to the minimum value of the first derivative of voltage. $p$ Values were calculated using two-tailed unpaired Student's $t$ test, NS, not significant.

and that observed in Figure 3. Lm128C neurons, both Lm128C/ $\mathrm{PV}^{-}$and $\mathrm{LM} 128 \mathrm{C} / \mathrm{PV}^{+}$subtypes, appear to have slightly narrower spikes than $\mathrm{PV}^{+}$neurons; however, the difference is not significant (Fig. 4C). Together, these results demonstrate that Lm128C cells exhibit fast-spiking electrophysiological properties that are traditionally associated with GABAergic $\mathrm{PV}^{+}$interneurons.

Although both PV and SST cells can exhibit a fast-firing and narrow spike shape phenotype, previous studies have demonstrated that these two cell types can be differentiated by two additional electrophysiological features, the adaptation ratio (Large et al., 2016) and the membrane voltage sag (Yavorska and Wehr, 2016). We estimated the membrane voltage sag associated with a step hyperpolarization as the absolute difference between the steady-state decrease in voltage and the largest decrease in voltage following a hyperpolarizing current step. Specifically, sag is calculated as the average voltage during the first $50 \mathrm{~ms}$ in response to a $-50 \mathrm{pA}$ current injection, subtracted from the last $100 \mathrm{~ms}$ of the $-50 \mathrm{pA}$ current injection step. We found no differences among the three groups in terms of the size of the membrane voltage sag (Fig. $4 C$ ). In contrast, the adaptation ratio, calculated as the ratio of interspike intervals during the last $100 \mathrm{~ms}$ of spiking divided by the first $100 \mathrm{~ms}$ of spiking, was significantly greater in $\mathrm{LM} 128 \mathrm{C} / \mathrm{PV}^{-}$cells than in $\mathrm{LM} 128 \mathrm{C} / \mathrm{PV}^{+}$neurons (Fig. 4D), consistent with previous observations in SST cells (Large et al., 2016). Together, these results further support the Patch-seq transcriptomic results that Lm128C cells are predominantly inhibitory neurons of the PV and SST subtypes. 
A

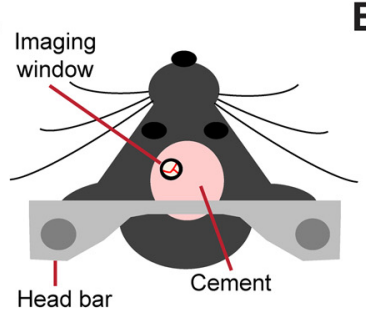

D
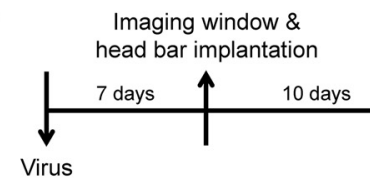

injection
B

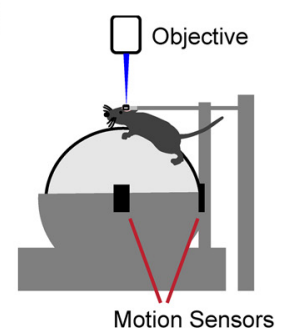

In vivo In vivo recording 1 recording 2 recording 1 recording

Habituation to recording set-up

C

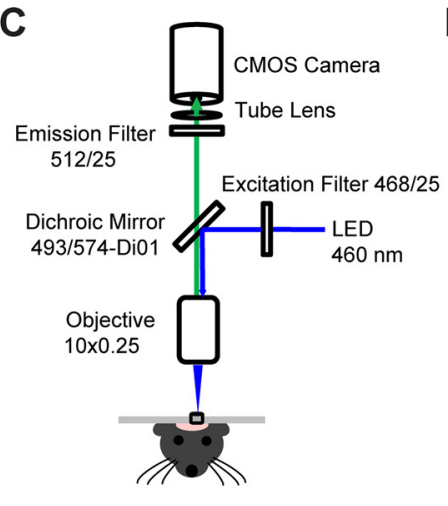

E

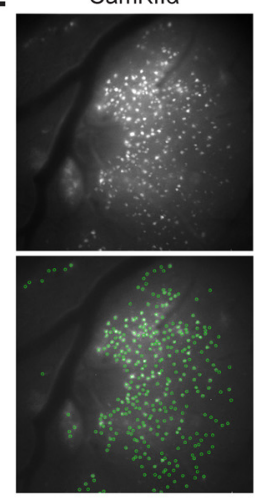

G
$\mathbf{F}$

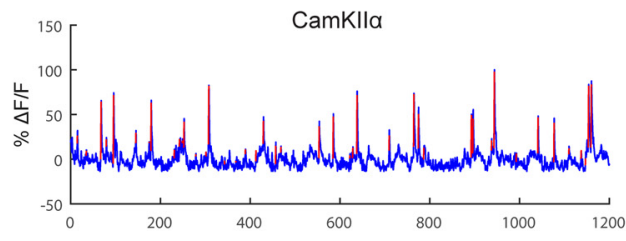

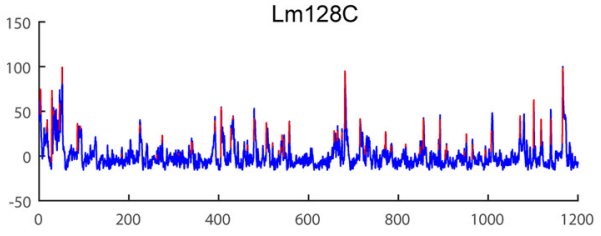
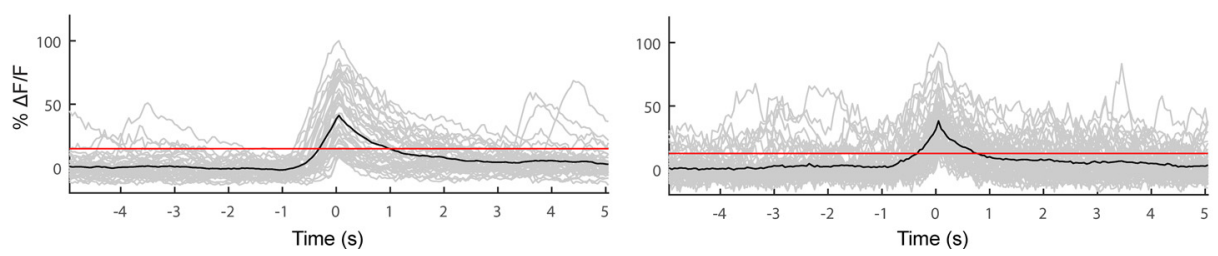
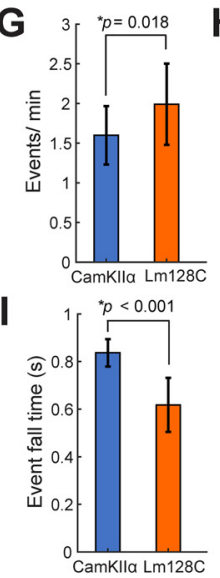

Lm128C

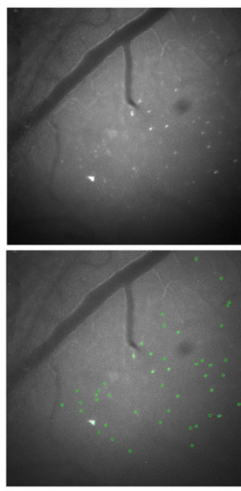

H
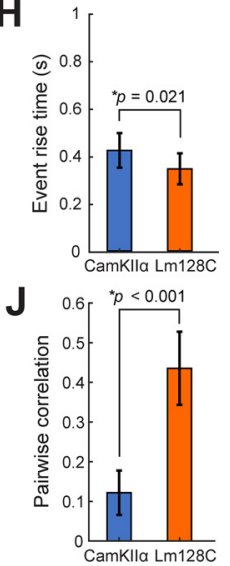

Figure 5. In vivo calcium imaging of overall CaMKIl $\alpha$ and $\mathrm{Lm} 128 \mathrm{C}$ neurons in motor cortex. $\boldsymbol{A}$, Schematic of an imaging window and a head bar implanted on the mouse head. $\boldsymbol{B}$, In vivo calcium imaging paradigm: animals were awake and head fixed under the imaging microscope during voluntary locomotion on a spherical treadmill. Two USB motion sensors were used for movement tracking. $\boldsymbol{C}$, Custom GCaMP6f imaging setup with an sCMOS camera. D, Experimental timeline for both the CaMKII $\alpha$ and $\mathrm{Lm} 128 \mathrm{C}$ mice groups. $\boldsymbol{E}$, Representative wide-field images from in vivo calcium imaging recordings (maximum-mean pixel intensity across all frames) for a CaMKIl $\alpha$ mouse (left) and an Lm128C mouse (right). Top, GCaMP6f fluorescence. Bottom, GCaMP6f fluorescence overlaid with manually identified ROls corresponding to individual GCaMP6f-expressing neurons. $\boldsymbol{F}$, Representative calcium traces (top) and waveforms (bottom) from a CaMKII $\alpha$ neuron (left) and an $\mathrm{Lm128C}$ neuron (right). Black traces (bottom) represent the average event waveform, and the red line indicates the average activation threshold. $\mathbf{G}-\mathbf{J}$, Calcium event rate $(\boldsymbol{G})$, event rise time $(\boldsymbol{H})$, and fall time $(\boldsymbol{I})$, and intrapopulation pairwise correlation for the overall CaMKIl $\alpha$ population and Lm128C neurons $(\boldsymbol{J})$. Bar plots represent the mean \pm SD across recording sessions ( $n=10$ recording sessions for each group, 2 recording sessions/mouse; $n=5$ mice/group), $p$ values were determined via a two-tailed unpaired Student's $t$ test.

Lm128C cells exhibit distinct calcium event dynamics, event rate, and pairwise correlation during locomotion compared with overall CaMKII $\alpha$ neurons in mouse motor cortex

To illustrate the utility of the mAGNET labeling strategy in functional analysis of neurons during behavior, we performed calcium imaging from Lm128C versus overall CaMKIIa cell populations in mice during locomotion. Since Lm128C cells comprise a minor fraction ( $\sim 8 \%$; Fig. $1 G)$ of the neurons labeled in CaMKII $\alpha$ animals, the effects observed in CaMKII $\alpha$ animals are primarily dominated by neurons with high levels of miR-128. Thus, our labeling scheme allows us to differentiate the physiological differences between neurons with high and low levels of miR-128 expression.

The experimental timeline for in vivo calcium imaging recordings is summarized in Figure $5 D$. First, mice were coinjected with a combination of AAVs (Fig. $1 A, B$ ), including the genetically encoded calcium indicator GCaMP6f targeted either to the population of overall CaMKII $\alpha$ neurons ("CaMKII $\alpha$ " animals) or specifically to CaMKII $\alpha$ neurons with low miR-128 ("Lm128C" animals) using the AAV-Lm128C-mAGNET vector (Fig. $1 A, B$ ). We later implanted a head bar and an imaging window centered over the injection site in motor cortex (Fig. 5A). During in vivo calcium imaging, mice were awake, head fixed, and engaged in voluntary locomotion on a spherical treadmill
(Dombeck et al., 2007; Mohammed et al., 2016; Gritton et al., 2019) positioned under a wide-field fluorescence microscope (Fig. 5B,C).

We motion corrected GCaMP6f fluorescence videos, manually selected ROIs from the maximum mean fluorescence intensity images (Fig. 5E), extracted the normalized fluorescence intensity traces for these ROIs, and identified individual calcium events. Consistent with the trend observed in the postfixed brain slices (Fig. 1), recordings from CaMKII $\alpha$ mice contained as many as approximately six times the number of GCaMP6fexpressing neurons as recordings from Lm128C mice (Fig. 5E, compare right, left). We found that the calcium event rate was significantly elevated for Lm128C neurons, compared with the overall CaMKII $\alpha$ population (Fig. $5 G$ ). In addition, the durations of calcium events were significantly shorter for Lm128C neurons compared with the CaMKII $\alpha$ population, with faster rise and fall times (Fig. 5F,H,I), suggesting that these neurons exhibit faster intracellular calcium dynamics. Furthermore, Lm128C neurons show significantly elevated pairwise correlation with other Lm128C cells when compared with the correlation among the overall population of CaMKII $\alpha$ neurons (Fig. $5 J$ ). Overall, the features exhibited by Lm128C neurons in behaving mice, including elevated event frequency, faster event dynamics, and greater synchrony, are typically associated with nonpyramidal interneu- 
A1

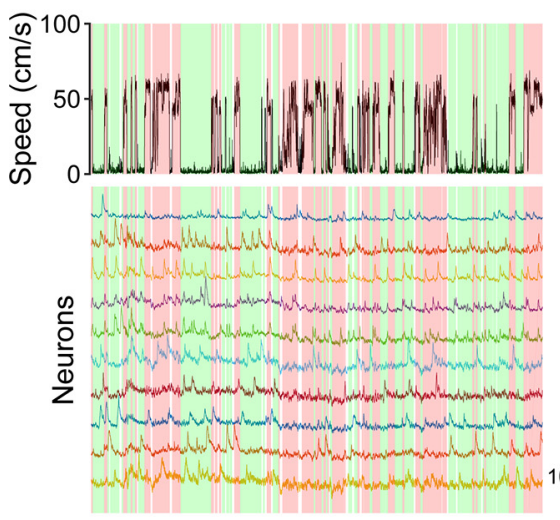

B

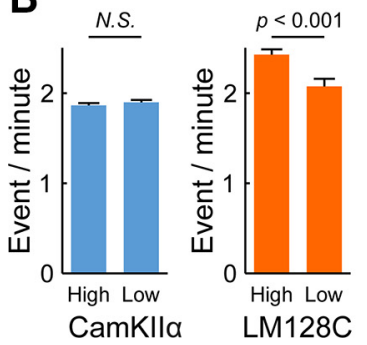

C

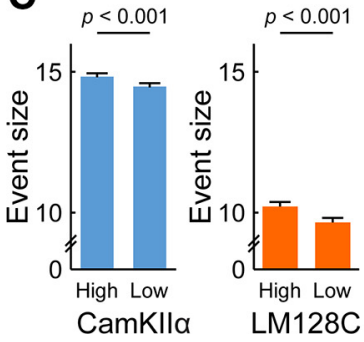

A2

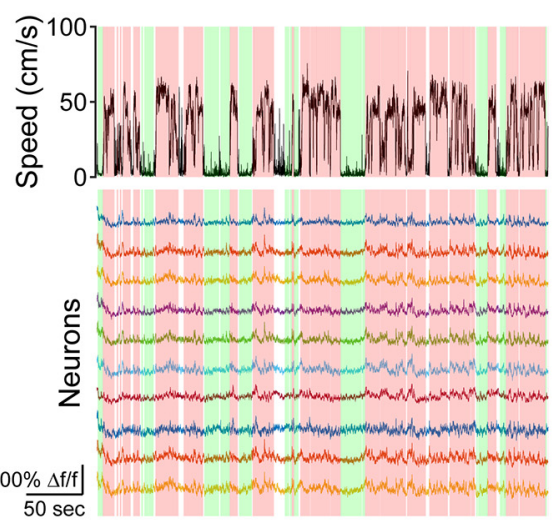

D

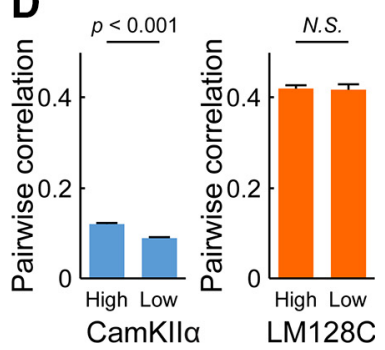

Figure 6. Differential modulation of calcium activity by movement speed in the overall CaMKIl $\alpha$ population and Lm128C neurons in the motor cortex. A1, A2, Representative examples of mouse movement speed and corresponding calcium traces during a recording session, for a CaMKIl $\alpha$ mouse $(\boldsymbol{A} 1)$ and a Lm128C mouse (A2). Periods of high-speed movement are highlighted in red, and periods of low-speed movement are highlighted in green. $\boldsymbol{B}-\boldsymbol{D}$, Event rate (events per minute; $\boldsymbol{B}$ ), event size (area under the curve; $\boldsymbol{C}$ ), and intrapopulation pairwise correlation ( $\boldsymbol{D}$ ) during periods of high-speed and low-speed movement for the overall CaMKII $\alpha$ population and $\operatorname{Lm} 128 \mathrm{C}$ neurons. Bar plots present the mean \pm SE (CaMKIl $\alpha$ : $n=1850$ neurons for $\boldsymbol{B}$ and $\boldsymbol{D}$, $n=1659$ neurons for $\boldsymbol{C}$, Lm128C: $n=330$ neurons for $\boldsymbol{B}$ and $\boldsymbol{D}, n=322$ neurons for $\boldsymbol{C} ; n=5$ mice for (aMKII $\alpha$ group, and $n=5$ mice for Lm128C group; two-tailed paired Student's $t$ test), NS, not significant.

rons in the cortex (Chen et al., 1996; Hu and Agmon, 2015), consistent with our Patch-seq transcriptomic analysis and electrophysiological characterizations in brain slices (Figs. 2-4).

\section{Lm128C cells are distinctly modulated by movement} compared with overall CaMKII $\alpha$ neurons during locomotion Because motor cortex neurons are known to be modulated by movement, we examined whether the overall CaMKII $\alpha$ neurons and Lm128C neurons exhibit distinct relationships with movement parameters. We identified periods when mice were moving at high speed $(>5 \mathrm{~cm} / \mathrm{s}$ for at least $1 \mathrm{~s})$ versus at low speed $(<5$ $\mathrm{cm} / \mathrm{s}$ for at least $1 \mathrm{~s}$ ) and compared calcium responses of the overall CaMKII $\alpha$ cells and Lm128C neurons during these time periods (Fig. 6A). We found that Lm128C neurons exhibited significantly elevated event rate during periods of high-speed movement, whereas the overall CaMKII $\alpha$ neuron population exhibited similar event rates during both periods (Fig. 6B). In addition, both the overall CaMKII $\alpha$ population and $\mathrm{Lm} 128 \mathrm{C}$ neurons exhibited larger event size, calculated as the area under the waveform, during high-speed movement compared with that during low-speed movement (Fig. 6C). These results are consistent with the general observation that many motor cortex neurons increase their activity when movement is more rigorous (Armstrong and Drew, 1984; Ebina et al., 2018). The fact that Lm128C neurons showed a significant increase in event rate, but not the overall CaMKII $\alpha$ neuron population, may be related to the fact that Lm128C neurons have shorter event duration. Interestingly, we also found that the overall CaMKII $\alpha$ population exhibited greater pairwise correlation during high-speed movement compared with that during low-speed movement, whereas
Lm128C cells showed no change in pairwise correlation (Fig. $6 D)$. Together, these results demonstrate that the overall CaMKII $\alpha$ population and Lm128C neurons were both positively modulated by movement speed. The overall CaMKII $\alpha$ population could further increase their intrapopulation correlation when movement speed increases, whereas Lm128C neurons showed no change in correlation when movement speed changes.

\section{Discussion}

We here demonstrate a novel viral gene expression strategy, using mAGNET designs, combinatorial with traditional promotor-based strategies, for targeted gene expression in neurons with specific endogenous miRNA expression profiles. This strategy enables in vivo labeling and functional characterization of unique neuron populations. Using this viral strategy, we labeled a subtype of CaMKII $\alpha^{+}$inhibitory interneurons on the basis of miRNA profile (low miR-128) and illustrated their unique electrophysiological and calcium activity patterns in mouse motor cortex. This study provides direct evidence that CaMKII $\alpha$ is present in a set of inhibitory neurons, and identified a novel neural subtype characterized on the basis of miRNA profile in vivo. Importantly, this study opens the door for a new avenue of studying cells with distinct expression profiles through miRNA regulation. As single-cell analysis tools provide increasing insight into the gene expression diversity of neurons, including miRNA profile data, we expect that miRNAs will emerge as important cellular markers. Furthermore, as the regulation networks of individual miRNAs are further explored, this will in turn allow the design of mAGNETs to delineate unique neuron subtypes whose physiological properties can be readily related to the miRNA gene regulatory networks dictated by the classification method. 
We designed mAGNET AAV viral vectors containing the CaMKII $\alpha$ promoter to label a subset of CaMKII $\alpha^{+}$neurons with naturally low expression of miR-128 (low-miRNA-128 CaMKII $\alpha$ cells, Lm128C cells). CaMKII is a serine/threonine kinase essential for synaptic plasticity and memory, and a major component of the postsynaptic density in many neurons (Herring and Nicoll, 2016). The $\alpha$ subunit (CaMKII $\alpha$ ) is generally regarded as a marker gene for pyramidal excitatory neurons in the mammalian cortex (Benson et al., 1992; Jones et al., 1994; Han et al., 2009; Nathanson et al., 2009; Han, 2012; Liu and Murray, 2012), although little is known about the gene expression diversity among cortical $\mathrm{CaMKII} \alpha^{+}$neurons. Among the miRNAs expressed in mammalian neocortical CaMKII $\alpha^{+}$neurons, miR-128 has been shown to be the second most highly expressed (He et al., 2012) and, overall, is one of the most abundant miRNAs in the mammalian brain (Lagos-Quintana et al., 2002). This miRNA has been shown to regulate gene networks that govern neuronal excitability(Tan et al., 2013), and the fast-spiking feature observed in Lm128C cells is consistent with the role of miR-128 in regulating membrane excitability. Thus, miRNA-based viral vector designs integrating miRNA regulation and promoter sequences represent a novel strategy to study the functions of cells with more defined gene expression profiles.

It is interesting to observe the expression of CaMKII $\alpha$ in GABAergic cortical interneurons, whose properties have not been specifically characterized previously. Over the years, in situ hybridization and immunolabelling of CaMKII $\alpha$ and Gad1 (the rate-limiting enzyme for GABA production) in the mammalian cortex have suggested that these proteins are expressed in mutually exclusive cells (Benson et al., 1992; Jones et al., 1994). For these reasons, CaMKII $\alpha$ has come to be associated with cortical excitatory cells. The fact that we found a small, yet distinct, population of cortical inhibitory neurons that express CaMKII $\alpha$ demonstrates that $\mathrm{CaMKII} \alpha$ is not as specific for excitatory neurons as commonly believed. Although CaMKII $\alpha$ has been associated with principal excitatory neurons in the mammalian cortex, its primary function in mediating postsynaptic long-term potentiation is not inherently specific to excitatory neurons (Herring and Nicoll, 2016). While extensive work has been directed toward the involvement of CaMKII at excitatory synapses, this does not preclude the expression of CaMKII in interneurons.

Similarly, PV has been widely adopted as a marker gene for a subset of GABAergic cells known as fast-spiking interneurons (Celio, 1986) and has therefore been assumed to not express CaMKII $\alpha$. However, CaMKII $\alpha$ and GAD are known to colocalize in neurons within some brain regions, such as the stria terminalis and cerebellum (Benson et al., 1992; Liu and Murray, 2012). Several recent studies suggest that there may be greater heterogeneity and overlap between cortical neurons expressing traditional excitatory and inhibitory genetic markers than previously thought. For example, Nathanson et al. (2009) reported that some $\mathrm{GAD} 7^{+}$neurons were labeled in mouse somatosensory cortex with the CaMKII $\alpha$ promoter delivered from an AAV2.1 vector, although they did not further characterize these cells. Furthermore, single-cell transcriptomic profiling of cortical neurons has recently been used to identify seven transcriptionally distinct subsets of $\mathrm{PV}^{+}$neurons in mouse primary visual cortex and acknowledged the existence of cells that coexpress a combination of markers including the excitatory marker $S l c 7 a 7$ as well as the inhibitory markers Gad1, Gad2, and PV (Tasic et al., 2016).

\section{References}

Armstrong DM, Drew T (1984) Discharges of pyramidal tract and other motor cortical neurones during locomotion in the cat. J Physiol 346:471-495.
Bak M, Silahtaroglu A, Møller M, Christensen M, Rath MF, Skryabin B, Tommerup N, Kauppinen S (2008) MicroRNA expression in the adult mouse central nervous system. RNA 14:432-444.

Bartel DP (2009) MicroRNAs: target recognition and regulatory functions. Cell 136:215-233.

Belgard TG, Marques AC, Oliver PL, Abaan HO, Sirey TM, HoerderSuabedissen A, García-Moreno F, Molnár Z, Margulies EH, Ponting CP (2011) A transcriptomic atlas of mouse neocortical layers. Neuron 71:605-616.

Benson DL, Isackson PJ, Gall CM, Jones EG (1992) Contrasting patterns in the localization of glutamic acid decarboxylase and $\mathrm{Ca} 2+/$ calmodulin protein kinase gene expression in the rat central nervous system. Neuroscience 46:825-849.

Cahoy JD, Emery B, Kaushal A, Foo LC, Zamanian JL, Christopherson KS, Xing Y, Lubischer JL, Krieg PA, Krupenko SA, Thompson WJ, Barres BA (2008) A transcriptome database for astrocytes, neurons, and oligodendrocytes: a new resource for understanding brain development and function. J Neurosci 28:264-278.

Celio MR (1986) Parvalbumin in most gamma-aminobutyric acid-containing neurons of the rat cerebral cortex. Science 231:995-997.

Chen TW, Wardill TJ, Sun Y, Pulver SR, Renninger SL, Baohan A, Schreiter ER, Kerr RA, Orger MB, Jayaraman V, Looger LL, Svoboda K, Kim DS (2013) Ultrasensitive fluorescent proteins for imaging neuronal activity. Nature 499:295-300.

Chen W, Zhang JJ, Hu GY, Wu CP (1996) Electrophysiological and morphological properties of pyramidal and nonpyramidal neurons in the cat motor cortex in vitro. Neuroscience 73:39-55.

Colin A, Faideau M, Dufour N, Auregan G, Hassig R, Andrieu T, Brouillet E, Hantraye P, Bonvento G, Déglon N (2009) Engineered lentiviral vector targeting astrocytes in vivo. Glia 57:667-679.

DeFelipe J, López-Cruz PL, Benavides-Piccione R, Bielza C, Larrañaga P, Anderson S, Burkhalter A, Cauli B, Fairén A, Feldmeyer D, Fishell G, Fitzpatrick D, Freund TF, González-Burgos G, Hestrin S, Hill S, Hof PR, Huang J, Jones EG, Kawaguchi Y, et al. (2013) New insights into the classification and nomenclature of cortical GABAergic interneurons. Nat Rev Neurosci 14:202-216.

Dittgen T, Nimmerjahn A, Komai S, Licznerski P, Waters J, Margrie TW, Helmchen F, Denk W, Brecht M, Osten P (2004) Lentivirus-based genetic manipulations of cortical neurons and their optical and electrophysiological monitoring in vivo. Proc Natl Acad Sci U S A 101:18206-18211.

Dobin A, Davis CA, Schlesinger F, Drenkow J, Zaleski C, Jha S, Batut P, Chaisson M, Gingeras TR (2013) STAR: ultrafast universal RNA-seq aligner. Bioinformatics 29:15-21.

Dombeck DA, Khabbaz AN, Collman F, Adelman TL, Tank DW (2007) Imaging large-scale neural activity with cellular resolution in awake, mobile mice. Neuron 56:43-57.

Ebina T, Masamizu Y, Tanaka YR, Watakabe A, Hirakawa R, Hirayama Y, Hira R, Terada SI, Koketsu D, Hikosaka K, Mizukami H, Nambu A, Sasaki E, Yamamori T, Matsuzaki M (2018) Two-photon imaging of neuronal activity in motor cortex of marmosets during upper-limb movement tasks. Nat Commun 9:1879.

Economo MN, Viswanathan S, Tasic B, Bas E, Winnubst J, Menon V, Graybuck LT, Nguyen TN, Smith KA, Yao Z, Wang L, Gerfen CR, Chandrashekar J, Zeng H, Looger LL, Svoboda K (2018) Distinct descending motor cortex pathways and their roles in movement. Nature 563:79-84.

Ferrante M, Tahvildari B, Duque A, Hadzipasic M, Salkoff D, Zagha EW, Hasselmo ME, McCormick DA (2017) Distinct functional groups emerge from the intrinsic properties of molecularly identified entorhinal interneurons and principal cells. Cereb Cortex 27:3186-3207.

Gonzalez-Sulser A, Parthier D, Candela A, McClure C, Pastoll H, Garden D, Surmeli G, Nolan MF (2014) GABAergic projections from the medial septum selectively inhibit interneurons in the medial entorhinal cortex. J Neurosci 34:16739-16743.

Gouwens NW, Sorensen SA, Baftizadeh F, Budzillo A, Lee BR, Jarsky T, Alfiler L, Arkhipov A, Baker K, Barkan E, Berry K, Bertagnolli D, Bickley K, Bomben J, Braun T, Brouner K, Casper T, Crichton K, Daigle TL, Dalley R, et al. (2020) Toward an integrated classification of neuronal cell types: morphoelectric and transcriptomic characterization of individual GABAergic cortical neurons. bioRxiv. Advance online publication. Retrieved November 8, 2020. doi: 10.1101/2020.02.03.932244.

Gritton HJ, Howe WM, Romano MF, DiFeliceantonio AG, Kramer MA, Saligrama V, Bucklin ME, Zemel D, Han X (2019) Unique contributions 
of parvalbumin and cholinergic interneurons in organizing striatal networks during movement. Nat Neurosci 22:586-597.

Han X (2012) Optogenetics in the nonhuman primate. Prog Brain Res 196:215-233.

Han X, Qian X, Bernstein JG, Zhou HH, Franzesi GT, Stern P, Bronson RT, Graybiel AM, Desimone R, Boyden ES (2009) Millisecond-timescale optical control of neural dynamics in the nonhuman primate brain. Neuron 62:191-198.

Harraz MM, Dawson TM, Dawson VL (2011) MicroRNAs in Parkinson's disease. J Chem Neuroanat 42:127-130.

Hawrylycz MJ, Lein ES, Guillozet-Bongaarts AL, Shen EH, Ng L, Miller JA, van de Lagemaat LN, Smith KA, Ebbert A, Riley ZL, Abajian C, Beckmann CF, Bernard A, Bertagnolli D, Boe AF, Cartagena PM, Chakravarty MM, Chapin M, Chong J, Dalley RA, et al. (2012) An anatomically comprehensive atlas of the adult human brain transcriptome. Nature 489:391-399.

He M, Liu Y, Wang X, Zhang MQ, Hannon GJ, Huang ZJ (2012) Cell-typebased analysis of microRNA profiles in the mouse brain. Neuron 73:35-48.

Herring BE, Nicoll RA (2016) Long-term potentiation: from CaMKII to AMPA receptor trafficking. Annu Rev Physiol 78:351-365.

Hodge RD, Bakken TE, Miller JA, Smith KA, Barkan ER, Graybuck LT, Close JL, Long B, Johansen N, Penn O, Yao Z, Eggermont J, Hollt T, Levi BP, Shehata SI, Aevermann B, Beller A, Bertagnolli D, Brouner K, Casper $\mathrm{T}$, et al. (2019) Conserved cell types with divergent features in human versus mouse cortex. Nature 573:61-68.

Hu H, Agmon A (2015) Properties of precise firing synchrony between synaptically coupled cortical interneurons depend on their mode of coupling. J Neurophysiol 114:624-637.

Jones EG, Huntley GW, Benson DL (1994) Alpha calcium/calmodulin-dependent protein kinase II selectively expressed in a subpopulation of excitatory neurons in monkey sensory-motor cortex: comparison with GAD-67 expression. J Neurosci 14:611-629.

Karali M, Manfredi A, Puppo A, Marrocco E, Gargiulo A, Allocca M, Corte MD, Rossi S, Giunti M, Bacci ML, Simonelli F, Surace EM, Banfi S, Auricchio A (2011) MicroRNA-restricted transgene expression in the retina. PLoS One 6:e22166.

Keaveney MK, Tseng HA, Ta TL, Gritton HJ, Man HY, Han X (2018) A microRNA-based gene-targeting tool for virally labeling interneurons in the rodent cortex. Cell Rep 24:294-303.

Lagos-Quintana M, Rauhut R, Yalcin A, Meyer J, Lendeckel W, Tuschl T (2002) Identification of tissue-specific microRNAs from mouse. Curr Biol 12:735-739.

Lam AJ, St-Pierre F, Gong Y, Marshall JD, Cranfill PJ, Baird MA, McKeown MR, Wiedenmann J, Davidson MW, Schnitzer MJ, Tsien RY, Lin MZ (2012) Improving FRET dynamic range with bright green and red fluorescent proteins. Nat Methods 9:1005-1012.

Large AM, Kunz NA, Mielo SL, Oswald AM (2016) Inhibition by somatostatin interneurons in olfactory cortex. Front Neural Circuits 10:62.

Lawrence M, Huber W, Pagès H, Aboyoun P, Carlson M, Gentleman R, Morgan MT, Carey VJ (2013) Software for computing and annotating genomic ranges. PLoS Comput Biol 9:e1003118.

Lin JY, Knutsen PM, Muller A, Kleinfeld D, Tsien RY (2013) ReaChR: a redshifted variant of channelrhodopsin enables deep transcranial optogenetic excitation. Nat Neurosci 16:1499-1508.

Liu XB, Murray KD (2012) Neuronal excitability and calcium/calmodulindependent protein kinase type II: location, location, location. Epilepsia 53 [Suppl 1]:45-52.

Macosko EZ, Basu A, Satija R, Nemesh J, Shekhar K, Goldman M, Tirosh I, Bialas AR, Kamitaki N, Martersteck EM, Trombetta JJ, Weitz DA, Sanes JR, Shalek AK, Regev A, McCarroll SA (2015) Highly parallel genomewide expression profiling of individual cells using nanoliter droplets. Cell 161:1202-1214

McCormick DA, Connors BW, Lighthall JW, Prince DA (1985) Comparative electrophysiology of pyramidal and sparsely spiny stellate neurons of the neocortex. J Neurophysiol 54:782-806.

Minami K, Uehara T, Morikawa Y, Omura K, Kanki M, Horinouchi A, Ono A, Yamada H, Ohno Y, Urushidani T (2014) miRNA expression atlas in male rat. Sci Data 1:140005.
Mohammed AI, Gritton HJ, Tseng HA, Bucklin ME, Yao Z, Han X (2016) An integrative approach for analyzing hundreds of neurons in task performing mice using wide-field calcium imaging. Sci Rep 6:20986.

Nathanson JL, Yanagawa Y, Obata K, Callaway EM (2009) Preferential labeling of inhibitory and excitatory cortical neurons by endogenous tropism of adeno-associated virus and lentivirus vectors. Neuroscience 161:441-450.

Pfister EL, DiNardo N, Mondo E, Borel F, Conroy F, Fraser C, Gernoux G, Han X, Hu D, Johnson E, Kennington L, Liu P, Reid SJ, Sapp E, Vodicka P, Kuchel T, Morton AJ, Howland D, Moser R, Sena-Esteves M, et al. (2018) Artificial miRNAs reduce human mutant Huntingtin throughout the striatum in a transgenic sheep model of Huntington's disease. Hum Gene Ther 29:663-673.

Pollen AA, Nowakowski TJ, Shuga J, Wang X, Leyrat AA, Lui JH, Li N, Szpankowski L, Fowler B, Chen P, Ramalingam N, Sun G, Thu M, Norris M, Lebofsky R, Toppani D, Kemp DW 2nd, Wong M, Clerkson B, Jones $\mathrm{BN}$, et al. (2014) Low-coverage single-cell mRNA sequencing reveals cellular heterogeneity and activated signaling pathways in developing cerebral cortex. Nat Biotechnol 32:1053-1058.

Reed ER, Latourelle JC, Bockholt JH, Bregu J, Smock J, Paulsen JS, Myers RH (2018) MicroRNAs in CSF as prodromal biomarkers for Huntington disease in the PREDICT-HD study. Neurology 90:e264-e272.

Roy AL, Conroy R, Smith J, Yao Y, Beckel-Mitchener AC, Anderson JM, Wilder EL (2018) Accelerating a paradigm shift: the common fund single cell analysis program. Sci Adv 4:eaat8573.

Sayeg MK, Weinberg BH, Cha SS, Goodloe M, Wong WW, Han X (2015) Rationally designed microRNA-based genetic classifiers target specific neurons in the brain. ACS Synth Biol 4:788-795.

Sugino K, Hempel CM, Miller MN, Hattox AM, Shapiro P, Wu C, Huang ZJ, Nelson SB (2006) Molecular taxonomy of major neuronal classes in the adult mouse forebrain. Nat Neurosci 9:99-107.

Suter BA, Migliore M, Shepherd GM (2013) Intrinsic electrophysiology of mouse corticospinal neurons: a class-specific triad of spike-related properties. Cereb Cortex 23:1965-1977.

Tan CL, Plotkin JL, Venø MT, von Schimmelmann M, Feinberg P, Mann S, Handler A, Kjems J, Surmeier DJ, O'Carroll D, Greengard P, Schaefer A (2013) MicroRNA-128 governs neuronal excitability and motor behavior in mice. Science 342:1254-1258.

Tasic B, Menon V, Nguyen TN, Kim TK, Jarsky T, Yao Z, Levi B, Gray LT, Sorensen SA, Dolbeare T, Bertagnolli D, Goldy J, Shapovalova N, Parry S, Lee C, Smith K, Bernard A, Madisen L, Sunkin SM, Hawrylycz M, et al. (2016) Adult mouse cortical cell taxonomy revealed by single cell transcriptomics. Nat Neurosci 19:335-346.

Tasic B, Yao Z, Graybuck LT, Smith KA, Nguyen TN, Bertagnolli D, Goldy J, Garren E, Economo MN, Viswanathan S, Penn O, Bakken T, Menon V, Miller J, Fong O, Hirokawa KE, Lathia K, Rimorin C, Tieu M, Larsen R, et al. (2018) Shared and distinct transcriptomic cell types across neocortical areas. Nature 563:72-78.

Tremblay R, Lee S, Rudy B (2016) GABAergic interneurons in the neocortex: from cellular properties to circuits. Neuron 91:260-292.

Usoskin D, Furlan A, Islam S, Abdo H, Lönnerberg P, Lou D, HjerlingLeffler J, Haeggström J, Kharchenko O, Kharchenko PV, Linnarsson S, Ernfors P (2015) Unbiased classification of sensory neuron types by large-scale single-cell RNA sequencing. Nat Neurosci 18:145-153.

Xu B, Hsu PK, Stark KL, Karayiorgou M, Gogos JA (2013) Derepression of a neuronal inhibitor due to miRNA dysregulation in a schizophreniarelated microdeletion. Cell 152:262-275.

Yavorska I, Wehr M (2016) Somatostatin-expressing inhibitory interneurons in cortical circuits. Front Neural Circuits 10:76.

Zeisel A, Muñoz-Manchado AB, Codeluppi S, Lönnerberg P, Manno GL, Juréus A, Marques S, Munguba H, He L, Betsholtz C, Rolny C, CasteloBranco G, Hjerling-Leffler J, Linnarsson S (2015) Brain structure. Cell types in the mouse cortex and hippocampus revealed by single-cell RNAseq. Science 347:1138-1142.

Zeng H, Sanes JR (2017) Neuronal cell-type classification: challenges, opportunities and the path forward. Nat Rev Neurosci 18:530-546.

Zhang YK, Chen K, Sloan SA, Bennett ML, Scholze AR, O'Keeffe S, Phatnani HP, Guarnieri P, Caneda C, Ruderisch N, Deng S, Liddelow SA, Zhang C, Daneman R, Maniatis T, Barres BA, Wu JQ (2014) An RNA-sequencing transcriptome and splicing database of glia, neurons, and vascular cells of the cerebral cortex. J Neurosci 34:11929-11947. 